\title{
A Mouse Model of Tuberous Sclerosis: Neuronal Loss of Tsc1 Causes Dysplastic and Ectopic Neurons, Reduced Myelination, Seizure Activity, and Limited Survival
}

\author{
Lynsey Meikle, ${ }^{1 \star}$ Delia M. Talos,,${ }^{2 *}$ Hiroaki Onda, ${ }^{1}$ Kristen Pollizzi, ${ }^{1}$ Alexander Rotenberg, ${ }^{2}$ Mustafa Sahin, ${ }^{2}$ \\ Frances E. Jensen, ${ }^{2}$ and David J. Kwiatkowski ${ }^{1}$ \\ ${ }^{1}$ Division of Translational Medicine, Department of Medicine, Brigham and Women's Hospital and 2Department of Neurology, Children's Hospital, \\ Harvard Medical School, Boston, Massachusetts 02115
}

\begin{abstract}
Tuberous sclerosis (TSC) is a hamartoma syndrome caused by mutations in TSC1 or TSC2 in which cerebral cortical tubers and seizures are major clinical issues. We have engineered mice in which most cortical neurons lose Tscl expression during embryonic development. These Tsc1 mutant mice display several neurological abnormalities beginning at postnatal day 5 with subsequent failure to thrive and median survival of $35 \mathrm{~d}$. The mice also display clinical and electrographic seizures both spontaneously and with physical stimulation, and some seizures end in a fatal tonic phase. Many cortical and hippocampal neurons are enlarged and/or dysplastic in the Tsc1 mutant mice, strongly express phospho-S6, and are ectopic in multiple sites in the cortex and hippocampus. There is a striking delay in myelination in the mutant mice, which appears to be caused by an inductive neuronal defect. This new TSC brain model replicates several features of human TSC brain lesions and implicates an important function of Tsc1/Tsc2 in neuronal development.
\end{abstract}

Key words: tuberous sclerosis; TSC1; mTOR; dysplastic neuron; ectopic neurons; seizures

\section{Introduction}

Tuberous sclerosis (TSC) is an autosomal dominant hamartoma syndrome in which involvement of the brain causes prominent neurologic symptoms (Gomez et al., 1999; Curatolo, 2003; Crino, 2004; DiMario, 2004). Cortical tubers, the hallmark TSC lesion in the brain, occur in nearly all TSC patients and are associated with a variety of forms of epilepsy, including infantile spasms (Thiele, 2004). Developmental delay and abnormal behavioral phenotypes, including autism, are also commonly seen in TSC (de Vries et al., 2005; Wiznitzer, 2004). Pathologically, cortical tubers are characterized by a regional loss of normal cortical architecture, with prominent giant cells that have enlarged nuclei and soma and are often multinucleated (Scheithauer and Reagan, 1999; Crino, 2004). Large numbers of disordered and dysplastic neurons are also seen within cortical tubers, as well as increased numbers of astrocytes (Crino, 2004; Miyata et al., 2004). A sec-

Received Dec. 21, 2006; revised April 13, 2007; accepted April 14, 2007.

This work was supported by the National Institutes of Health National Institute of Neurological Disorders and Stroke NS24279 (D.J.K.), NS31718 (F.E.J.), the Tuberous Sclerosis Alliance (L.M., D.M.T., M.S., F.E.J., D.J.K.), and the Rothberg Courage Fund (D.J.K.). We thank Thomas Diefenbach and the Developmental Disabilities Research Center imaging core for assistance with confocal microscopy, Rod Bronson for assistance with brain pathology, Victoria Walker for technical assistance, Larry Benowitz for useful discussions on GAP-43, and Vijaya Ramesh for providing the Tsc1 antibody.

*L.M. and D.M.T. contributed equally to this work.

Correspondence should be addressed to either of the following: David J. Kwiatkowski, One Blackfan Circle, 6-216, Division of Translational Medicine, Department of Medicine, Brigham and Women's Hospital, Boston, MA 02115 E-mail: dk@rics.bwh.harvard.edu; or Frances E. Jensen, Enders 348, Neurology, Children's Hospital, Boston, 300 Longwood Avenue, Boston, MA 02115, E-mail: frances.jensen@childrens.harvard.edu.

H. Onda's present address: Mouse Genome Informatics, The Jackson Laboratory, Bar Harbor, ME 04609.

D0I:10.1523/JNEUROSC1.5540-06.2007

Copyright $\odot 2007$ Society for Neuroscience $\quad$ 0270-6474/07/275546-13\$15.00/0 ond TSC brain lesion is the subependymal nodule, which is found lining the ventricular wall, typically in the lateral ventricles, and can progress to a subependymal giant cell tumor.

TSC is caused by inactivating mutations in either of TSC1 or TSC2 (Kwiatkowski and Manning, 2005). Mutations can be identified in one or the other of these two genes in $\sim 85 \%$ of TSC patients; the remainder are likely attributable to mosaicism or undetected mutations, as there is no evidence for a third gene (Kwiatkowski, 2003). The protein products of these genes, hamartin and tuberin, respectively, have been shown to play an important role in a conserved signaling pathway that regulates both cell size and cell growth (Astrinidis and Henske, 2005; Inoki et al., 2005; Kwiatkowski and Manning, 2005; Sarbassov et al., 2005; Tee and Blenis, 2005). Hamartin and tuberin form a complex, and a GTPase-activating protein (GAP) domain within tuberin functions to accelerate conversion of Rheb-GTP to RhebGDP. Rheb-GTP activates the mTORC1 kinase complex, which leads to both cell size enlargement and protein translation by phosphorylating several downstream effectors, including p70S6 kinase and 4E-BP1 (Holz et al., 2005). Biallelic inactivation of either TSC1 or TSC2 is seen in most hamartomas from TSC patients, corresponding to the germline mutation (Cheadle et al., 2000; Tucker and Friedman, 2002; Chan et al., 2004). Thus, in TSC lesions, there is loss of the hamartin-tuberin GAP activity with consequent constitutive activation of $\mathrm{mTORC} 1$ and its downstream effectors. One mTORC1 effector, p70S6 kinase, phosphorylates the ribosomal protein $\mathrm{S} 6$, and phospho-S6 (pS6) is present at high levels in TSC hamartomas (Goncharova et al., 2002; El-Hashemite et al., 2003). In contrast to hamartomas, the 
evidence for biallelic inactivation of TSC1 or TSC2 in cortical tubers has been very limited (Niida et al., 2001; Tucker and Friedman, 2002), and there is a suggestion of an alternative pathogenesis (Han et al., 2004). However, tuber giant cells express pS6 and other markers of mTORC1 activation at high levels, similar to subependymal giant cell astrocytomas (Baybis et al., 2004; Chan et al., 2004; Miyata et al., 2004).

We and others have generated and evaluated several rodent models of TSC. The Eker rat arose as a spontaneous inactivating mutation in Tsc 2 and has been shown to develop approximately one brain hamartoma per rat (Yeung et al., 1997; Wenzel et al., 2004). These lesions have some resemblance to the brain lesions occurring in TSC, but there is no associated clinical phenotype. $T s c 1^{w-}$ and $T s c 2^{w-}$ mice have been generated but develop no significant brain pathology (Onda et al., 2002). More recently, we have generated a conditional, floxed allele of $T s c 1\left(T s c 1^{c}\right)$ (Kwiatkowski et al., 2002; Meikle et al., 2005). Using this allele, mice lacking Tsc1 expression in astrocytes have been generated, and although these mice develop seizures and significant brain pathology, this model does not produce pathology similar to that seen in TSC cortical tubers (Uhlmann et al., 2002).

Here, we report the generation and characterization of a new brain model of TSC, using the $T s c 1^{c}$ allele. Tscl expression is ablated in most neurons beginning at approximately embryonic day 13 (E13) through use of a synapsin promoter to drive cre recombinase expression (Zhu et al., 2001). These mice display delayed development beginning at postnatal day 5 (P5), spontaneous seizures, shortened lifespan, and neuropathological abnormalities including ectopic, enlarged, and aberrant neurons in multiple locations. These abnormal neurons have features similar to the dysplastic neurons seen in TSC cortical tubers. Persistent hypomyelination is also seen in these mice, although axon and oligodendrocyte distribution appear normal.

\section{Materials and Methods}

Mouse procedures. Mouse experiments were performed in a mixed-strain background (129S4/SvJae, C57BL/6, and CBA) to accommodate the combination of alleles studied here. Mice bearing the SynI-cre allele were a generous gift from Jamey Marth (University of California, San Diego, La Jolla, CA) (Zhu et al., 2001). Mice were generated through breedings between $T s c 1^{c c}$ females and either $T s c 1^{w-}$ SynI-cre ${ }^{+}$or $T s c 1^{w-}$ SynI-cre ${ }^{++}$ males or between $T s c 1^{c c}$ males and $T s c 1^{c w} S y n I-c r e e^{+}$females. (We use $c, w$, and - to denote the conditional (floxed), wild-type, and null alleles of $T s c 1$, respectively; the formal name of the $c$ allele is Tsc1 ${ }^{\text {tm1Djk }}$.) All Tsc1 $1^{c c}$ mice used were also homozygous for a floxed $\beta$-galactosidase ( $\beta$-gal) reporter allele from which $\beta$-gal expression occurs only after cre recombination (Mao et al., 1999). Generation of the $T s c 1^{c}$ and $T s c 1^{-}$alleles was described previously (Kwiatkowski et al., 2002; Meikle et al., 2005). In the $T s c l^{c}$ allele, there are loxP sequences flanking exons 17 and 18 . When recombination occurs, deletion of these two exons leads to no Tsc1 protein expression, a null allele (Kwiatkowski et al., 2002). All procedures were performed in accordance with the Guide for the Humane Use and Care of Laboratory Animals, and the study was approved by the Harvard Medical Area Standing Committee on Animals and the Animal Care and Use Committee of Children's Hospital, Boston. Mice were killed when weight loss of $20 \%$, greatly reduced movement, or other signs of morbidity were seen.

DNA analyses. DNA was prepared from mouse toes/tails by standard procedures for genotyping. Genotyping at the $T s c 1$ gene was performed using a three-primer system that allows simultaneous analysis of both conditional and wild-type alleles, followed by agarose gel electrophoresis (Meikle et al., 2005). Primers that amplify a 300 bp portion of the cre recombinase were used to assess the presence of the SynI-cre allele (Meikle et al., 2005). Southern blot analysis was performed on brain DNA following standard methods (Kwiatkowski et al., 2002).
Antibodies. Antibodies used were as follows: S6K, Tsc2 (C20), Akt, and ERK2 (extracellular signal-regulated kinase 2) (Santa Cruz Biotechnology, Santa Cruz, CA); pS6 (S240/244), pS6 (S235/236), and Tsc1 (Cell Signaling Technology, Bedford, MA); NeuN (MAB377), glutamate decarboxylase 67 (GAD67; MAB351), galactocerebroside (GalC; MAB342), neurofilament (NF; MAB4245), myelin basic protein (MBP; AB980), growth-associated protein 43 (GAP-43; MAB347), nestin (MAB353), and neuron-specific enolase (NSE; AB951) (Millipore, Billerica, MA); GFAP (SMI 22), nonphosphorylated neurofilament (SMI 311), phosphorylated neurofilament (SMI 312), and MBP (SMI 99) (Sternberger Monoclonals, Lutherville, MD); O4 (gift from S. Pfeiffer, Farmington, CT); and Tsc1 (gift from V. Ramesh, Boston, MA).

Immunoblotting. Mice were killed at P21, and the whole brains were rapidly removed. Half-brains were isolated, snap frozen in liquid nitrogen, and stored at $-80^{\circ} \mathrm{C}$. Each frozen half-brain was homogenized in $5 \times$ volume TBSV lysis buffer [(in mM) 20 Tris-Cl, pH 7.5, $140 \mathrm{NaCl}, 10$ $\mathrm{NaF}, 1 \mathrm{Na}_{3} \mathrm{VO} 4$, and 1 EDTA] with $0.1 \%$ Triton $\mathrm{X}-100$, and one "Complete Mini” protease inhibitor mixture tablet (Roche, Indianapolis, IN) per $50 \mathrm{ml}$. Samples were then diluted in Laemmli's SDS-sample buffer. Proteins were separated by electrophoresis on $4-12 \%$ Bis-Tris gels (Novex; Invitrogen, Carlsbad, CA) and transferred onto trans-blot nitrocellulose membranes. Coomassie staining was performed to confirm that the samples were loaded equally. The membranes were blocked in 5\% nonfat dry milk in PBS, pH 7.4, with 0.1\% Tween 20 (PBS-Tween) for $1 \mathrm{~h}$ at room temperature. Primary antibodies were diluted in the blocking solution, and the membranes were incubated overnight at $4^{\circ} \mathrm{C}$. The primary antibody was removed, and the blots were washed in PBS-Tween and then incubated for $1 \mathrm{~h}$ at room temperature in horseradish peroxidase-conjugated secondary antibodies (Santa Cruz Biotechnology). Reactive proteins were visualized using SuperSignal West Pico chemiluminescence reagent (Pierce Biotechnology, Rockford, IL) and exposure to x-ray film (BioMax MR; Kodak, Rochester, NY). All immunoblots shown in one row of a figure are from the same gel-blot exposure.

Histological preparation and immunohistological staining of brain sections. Mice at ages P14 and P21 were anesthetized, and transcardiac perfusion was performed using PBS, followed by $4 \%$ paraformaldehyde (PFA) in PBS. Whole brains were then removed and postfixed overnight at $4^{\circ} \mathrm{C}$ in $4 \%$ PFA solution. P7 mice were anesthetized and decapitated, and whole brains were removed and fixed overnight at $4^{\circ} \mathrm{C}$ in the same $4 \%$ PFA solution. Paraffin sections were prepared for standard histological examination. For immunostaining, fixed brains were cryoprotected in $30 \%$ sucrose in PBS for $1-14 \mathrm{~d}$ at $4^{\circ} \mathrm{C}$, and coronal sections were cut at $50 \mu \mathrm{m}$ using a Microm K400 Fast Freezing Unit and HM 450 Sliding Electronic Microtome and were then stored in PBS at $4^{\circ} \mathrm{C}$ until use (Talos et al., 2006). Free-floating sections were incubated in blocking solution (PBS with $0.1 \%$ Triton X-100 and 5\% normal goat serum; except for GalC and O4, for which Triton X-100 was omitted) for $1 \mathrm{~h}$ at room temperature, followed by incubation with primary antibody overnight at $4^{\circ} \mathrm{C}$. After three $20 \mathrm{~min}$ PBS washes, sections were incubated in secondary antibody solution containing Alexa Fluor 568 goat anti-rabbit/antimouse IgG/IgM or Oregon green 488 goat anti-rabbit/anti-mouse IgG (Invitrogen), for $1 \mathrm{~h}$ at room temperature. After three washes in PBS, sections were mounted onto positively charged slides and coverslipped with antifade medium (Fluoromount-G; Southern Biotechnology, Birmingham, AL). Control sections were done with omission of one or both primary antibodies, adding both secondary antibodies, to establish specificity. Fluoro Jade B (AB310; Millipore) staining was performed on 50 $\mu \mathrm{m}$ free-floating sections following standard histological procedures (Schmued et al., 2005). Slides were viewed on a Nikon (Tokyo, Japan) TE2000-E inverted microscope equipped with $20 \times, 10 \times$, and $4 \times$ objectives. Illumination wavelength, intensity, and exposure times were selected using a dual filterwheel apparatus containing an electronically controlled shutter and filters for the different fluorophore wavelengths (Lambda 10-2; Sutter Instruments, Novato, CA). Digital images were captured using an Orca-II ER cooled CCD camera (Hamamatsu Photonics, Hamamatsu, Japan) and MetaMorph. Digital images were then processed and analyzed using Adobe (San Jose, CA) Photoshop, including pseudocolorization.

5-Bromo-4-chloro-3-indolyl- $\beta$-D-galactopyranoside (X-gal) staining 
of brain sections to assess $\beta$-gal expression was performed using a kit (Millipore) following the manufacturer's instructions. Immunoperoxidase staining on these same sections was performed after X-gal staining, using a three-step avidin-biotin-peroxidase system. After exposure to primary antibodies, sections were incubated in biotinylated secondary antibodies, followed by $\mathrm{ABC}$ reagent (Vectastain; Vector Laboratories, Orton Southgate, Peterborough, UK). Diaminobenzidine was used as substrate to detect bound peroxidase, and the reaction was stopped when a brown color appeared; incubation of all sections was terminated simultaneously. Slides were viewed on a Nikon Eclipse E400 microscope, and images were captured using Spot software v4.0.5.

For all histological and immunostaining observations, a minimum of three (range, 3-12) pairs of mutant and control mice were examined from stereotactically matched brain sections.

Confocal images were captured using a Zeiss (Thornwood, NY) LSM 510 scanning laser microscope with $20 \times$ and $63 \times$ objectives. For cell size determination, a $Z$-stack of confocal images at $0.5 \mu \mathrm{m}$ intervals was collected from the somatosensory cortex in layer $\mathrm{V}(-2$ to -2.2 $\mathrm{mm}$ from bregma and 3.2-3.4 $\mathrm{mm}$ lateral to midline) for each of two matched mutant and control mice. Images were examined using ImageJ software $1.31 \mathrm{v}$ (W. Rasband, National Institutes of Health, Bethesda, MD) to calculate cell size in pixels after manual drawing of cell margins. All SMI $311+$ cells in a $20 \times$ field were measured, independent of pS6 staining, for a minimum of eight cells per mouse. Measurements were compared using the Mann-Whitney $U$ test in Prism (GraphPad, San Diego, CA).

Mouse electroencephalogram methods. Mouse electroencephalogram (EEG) recordings were acquired with Teflon-coated silver/silver chloride (Ag/AgCl) subdermal wire electrodes (SWEs) (Ives, 2005). Three electrodes were positioned in the dorsal scalp: one wire at midline over the olfactory bulb and two wires over the left and right parietal regions. A fourth SWE was placed subcutaneously over the thorax to record the electrocardiogram (EKG). The electrodes were placed using 26 ga syringe needles as guides, but only the thin flexible electrode strands were left in the scalp and torso. Splayed wires at the terminus of the electrode kept wires in position during recording. The animals tolerated this procedure well and appeared in no acute distress at the time of electrode placement.

For the duration of the recording, the animals were gently restrained with broad straps and adhesive tape such that the torso and limbs were immobilized, but the head and tail had full freedom of movement to monitor for clinical seizures. The EEG signal was amplified and recorded using a Grass 15A94 amplifier with Grass Gamma 4.3 acquisition software (Grass-Telefactor, West Warwick, RI). Mice were monitored continuously by either video camera or direct observation, and movement artifact on tracings was minimal. For review, the tracings were filtered at $1-70 \mathrm{~Hz}$ and viewed as a bipolar montage of the three available cranial electrode pairs along with continuous EKG. The tracings were analyzed by a single electrophysiologist (A.R.) blinded to the animals' genotype.

\section{Results}

Neurodevelopment of mice with a deletion of Tsc1 in neurons To explore the effects of loss of $T s c 1$ in neurons, we interbred a conditional allele of $T s c 1\left(T s c 1^{c}\right)$ with a synapsin I promoterdriven cre recombinase allele (SynICre) that has been shown to lead to recombination of nearby loxP sites in the majority of neurons beginning at E12.5 (Zhu et al., 2001). Onset of cre recombinase expression at E12.5 and localization to spinal cord and
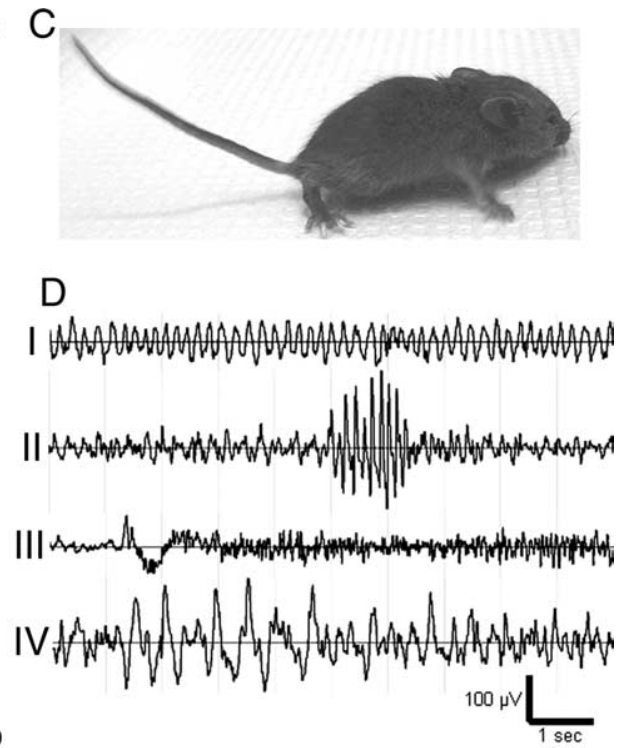

$\rightarrow-$ Control Cohort

- Tsc1c/-Synl Cre+
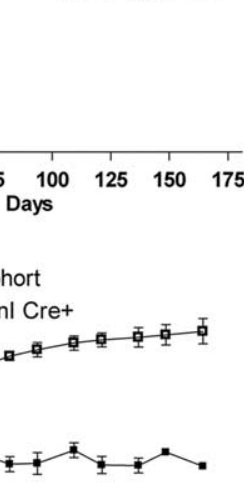

$40 \quad 50 \quad 60$

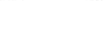

(1)

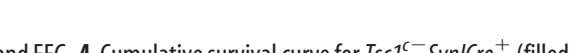

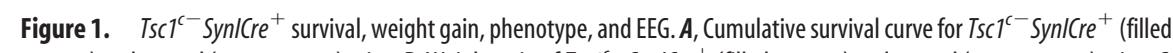
squrs) and control (open squares) mice. $\boldsymbol{B}$, Weight gain of $\mathrm{TsC}^{\mathrm{C}^{-}}$Syn/( $\mathrm{re}^{+}$(filled squares) and control (open squares) mice. $\boldsymbol{C}$ normal continuous control mouse background (I), a spike burst occurring in a somewhat irregular background in a mutant mouse (II), relative high-frequency desynchronization during a tonic seizure in a $\mathrm{ScC}^{\mathrm{c}-}$ Syn/Cre ${ }^{+}$mouse (III), and frequent high-amplitude sharp waves in a mutant mouse (IV).

brain was confirmed through use of a lacZ reporter allele (data not shown). Tsc1 ${ }^{c-}$ SynICre ${ }^{+}$mice were derived from breeding schemes that also generated $\mathrm{Tscl}^{\mathrm{cw}} \mathrm{SynICre} \mathrm{C}^{+}$and $\mathrm{Tscl}^{\mathrm{c}-}$ SynICre mice, which were used as controls ( $w$ denotes wild-type allele; denotes null allele). Control mice showed no phenotype, and $>95 \%$ survived $>6$ months. We chose to study $\mathrm{Tscl}^{c-}$ SynICre ${ }^{+}$ as opposed to $\mathrm{Tscl}^{c c} \mathrm{SynICre}{ }^{+}$mice, because the systemic loss of one allele of Tsc1 in the former matches the genotype of TSC patients with a mutation in TSC1.

$\mathrm{Tsc}^{c^{-}}$SynICre ${ }^{+}$mice were born in Mendelian ratios (19 of 79 pups were $\mathrm{Tscl}^{c-}$ SynICre ${ }^{+}$genotyped at P7 in one breeding scheme, compared with $25 \%$ expected) and were indistinguishable from control littermates until $\sim$ P5. Thereafter, they failed to gain weight at the same rate as control littermates. By P10, hyperactivity and an enhanced startle response were apparent, as well as a progressive high-frequency $(10-15 \mathrm{~Hz})$ trunk and limb tremor at rest. $\mathrm{Tscl}^{c^{-}}$SynICre ${ }^{+}$mice had a median survival of $35 \mathrm{~d}$, none survived past $65 \mathrm{~d}$, and their average maximum weight was $10 \mathrm{~g}$ (Fig. $1 A, B$ ).

Neurologic assessment indicated that $\mathrm{Tscl}^{\mathrm{c}^{-}} \mathrm{SynICre}{ }^{+}$mice had dorsiflexion of the tail (Straub tail) (Fig. 1C) and posterior limb-clasping behavior when lifted by their tails. Tsc1 ${ }^{c-}$ SynICre ${ }^{+}$ mice showed a progressive decline in activity with limited mobility and development of a humped posture, typically in the third or fourth week. Most deaths occurred in the third to fifth postnatal week, and mice were typically found postmortem in an extensor posture of both the forelimbs and hindlimbs.

\section{Seizure activity in mice with a deletion of Tsc1 in neurons}

In addition to the neurological abnormalities described above, $\mathrm{Tscl}^{c-}$ SynICre ${ }^{+}$mice also developed clinical seizures. Spontaneous seizure activity was seen in $\sim 10 \%$ of mice, but seizures were more consistently provoked by physical stimulation, such as handling and sudden movements of the cage. Two seizure types were observed. Severe seizures, seen both spontaneously and with han- 
dling, were characterized by a brief (1-3 s) behavioral arrest, followed by several seconds of clonic activity, followed by tonic extensor posturing of trunk and limbs for 15-45 s. When suspended by the tail after age P21, gentle spinning consistently led to this sequence of events followed by bradycardia and death. A second milder seizure type seen only spontaneously was brief myoclonic jerking of head and torso.

To further characterize the seizures of $\mathrm{Tscl}^{c-} \mathrm{SynICre}^{+}$mice, digital EEGs were recorded from seven mutant and 11 control littermates at ages $\mathrm{P} 21-\mathrm{P} 48$ for $1-3 \mathrm{~h}$. Control mice showed the expected 4-6 Hz background activity at rest with appropriate reactivity to salient stimuli (Fig. $1 D, \mathrm{I}$ ). Three electrographic abnormalities were recorded in the mutant mice: (1) short spike bursts (seven of seven mice), (2) spontaneous periods of desynchronization with electrodecrement (one of seven), and (3) frequent high-amplitude sharp waves (one of seven). The interictal $1-2 \mathrm{~s}$ bursts of high-amplitude $7-8 \mathrm{~Hz}$ spikes (Fig. $1 D$, II) seen in all mutants resembled pentylene tetrazole-triggered spikes in control mice (data not shown). Two short bursts of similar spikes were recorded in one of the 11 control mice $(p=0.0003$; Fisher exact test, compared with mutants). However, the average frequency of these epileptiform discharges was much higher in the $\mathrm{Tscl}^{c^{-}}$SynICre ${ }^{+}$mice (2.8 vs 0.1 bursts/h in controls; $p=.001$; Mann-Whitney). In six of seven $T s c 1^{c-}$ SynICre ${ }^{+}$mice, the spontaneous spike bursts were without obvious clinical correlate.

However, in one of seven $\mathrm{Tscl}^{c-}$ SynICre ${ }^{+}$mice, the spike bursts were temporally associated with myoclonic jerks of head and torso. The same animal also had a single unprovoked seizure characterized clinically by unresponsiveness with tonic stiffening of torso and tail. This was a fatal tonic seizure that led to bradycardia within $2 \mathrm{~s}$ of electrographic seizure onset and death $19 \mathrm{~s}$ after clinical onset. Electrographically, the seizure started as 12-14 Hz low-amplitude activity (Fig. 1 D, III) and evolved to 2-3 $\mathrm{Hz}$ rhythmic high-amplitude spikes, followed by reduction in EEG amplitude and ultimate loss of EEG signal, likely reflecting brain death. Additionally, four of four Tsc1 ${ }^{c-}$ SynICre ${ }^{+}$mice displayed an identical electroclinical sequence after gentle tail spinning.

One $\mathrm{Tscl}^{c-} \mathrm{SynICre}^{+}$mouse had frequent high-amplitude sharp waves throughout the recording period (Fig. 1D, IV). These were without clinical correlate and were neither rhythmic nor sustained sufficiently to qualify as electrographic seizures.

In aggregate, the observed electrographic abnormalities and clinical seizures, including two seizure types captured on EEG, indicate that the $\mathrm{Tscl}^{c-}$ SynICre ${ }^{+}$mice have a marked tendency toward early-onset epilepsy. We considered the possibility that poor feeding and/or metabolic factors might contribute to these EEG abnormalities and seizures. However, serum $\mathrm{Na}^{+}$, glucose, blood urea nitrogen, and $\mathrm{Ca}^{2+}$ levels at age $30 \mathrm{~d}$ were similar among $\mathrm{Tscl}^{c-}$ SynICre ${ }^{+}$mice and controls.

\section{Analysis of brain-specific recombination in Tsc1}

We confirmed that recombination at the $T s c 1^{c}$ allele occurred in the brains of the $\mathrm{Tscl}^{c-}$ SynICre ${ }^{+}$mice by several methods. First, Southern blot analysis indicated that there was substantial conversion of the $c$ to the - allele in cortex and diencephalon by age 3 weeks, whereas in contrast, relatively little recombination occurred in the cerebellum (Fig. 2A). Second, PCR analysis showed that there was substantial conversion of the $c$ allele to the - allele in brain DNA preparations from the mice (data not shown). Third, immunoblot analysis showed that there was a major reduction in the amount of Tsc1 and Tsc2 present in whole-brain homogenates prepared from the $T s c 1^{c-}$ SynICre ${ }^{+}$mice compared with controls (Fig. 2 B). Reduction in Tsc2 protein levels was expected, given its dependence on Tsc1 expression for stabilization (Benvenuto et al., 2000). Complete loss of Tsc1 expression would not be expected if recombination is restricted to neurons, as reported previously for this SynICre allele (Zhu et al., 2001). Also consistent with loss of Tsc1 was the marked increase in levels of pS6 in brain lysates (Fig. 2 B), a protein known to be phosphorylated at high levels in cells lacking Tsc1 or Tsc2 (Kwiatkowski et al., 2002; Onda et al., 2002; Tavazoie et al., 2005). Similar amounts of NeuN and NSE were seen in mutant and control brains, indicating that the overall amount of neuronal protein was similar in these brain homogenates.

\section{Cortical and hippocampal structural abnormalities in Tsc1 $^{c-}$ SynICre ${ }^{+}$mice}

Cortical tubers in TSC patients are characterized by a regional loss of normal cortical architecture and the presence of enlarged cells. Therefore, we asked whether cortical architecture was preserved in the $\mathrm{Tscl}^{c-}$ SynICre ${ }^{+}$mice. Hematoxylin and eosin (H\&E) staining of P21 coronal sections demonstrated that laminar organization in the cerebral cortex was less distinct in $\mathrm{TsCl}^{c-}$ SynICre ${ }^{+}$mice than in the six cortical layers of controls (Fig. $2 \mathrm{Ca}, \mathrm{Da}$ ). Furthermore, unusually large cells were seen in each of the six cortical layers in $\mathrm{Tscl}^{c-}$ SynICre ${ }^{+}$mice, particularly layer $\mathrm{V}$ (Fig. $2 \mathrm{Cb}, \mathrm{Db}$ ). In addition, in contrast to control cortex (Fig. 2Ca, Cc), a layer of enlarged cells was seen at the gray-white border throughout the mutant cortex at P21 (Fig. 2Da, asterisk, $D c$ ). These findings indicate cell enlargement in the neocortex of the $\mathrm{Tscl}^{c-}$ SynICre ${ }^{+}$ mice, similar to that seen in cortical tubers in TSC patients.

Because the hippocampal formation is associated with epileptic discharges in many mouse models, we also analyzed the cytoarchitecture of the hippocampus. Although overall the structural organization of the hippocampus was normal, enlarged cells were seen throughout the pyramidal cell layer, especially in the cornu ammonis 3 (CA3) region (data not shown) (see below). Many enlarged cells were also seen within the hilus of the dentate gyrus in mutant animals. Enlarged ectopic cells were also seen outside the CA1-CA3 fields in the stratum oriens and stratum radiatum (data not shown). In addition to the neocortex and the hippocampus, enlarged cells were also seen in other brain regions, including subcortical gray matter structures such as thalamus, hypothalamus, and brainstem. Despite these changes in cell distribution and size, there was no evidence of increased cell loss or degeneration in any brain area by H\&E staining, silver staining, or Fluoro Jade B staining (data not shown).

To confirm that recombination and loss of Tsc1, and subsequent mTORC1 activation, were occurring in the enlarged cells, we used a lacZ reporter allele. The X-gal blue precipitate was seen widely distributed in the cortex and hippocampus of both $\mathrm{Tscl}^{\mathrm{c}-}$ SynICre ${ }^{+}$and $\mathrm{Tscl}^{\mathrm{cw}} \mathrm{SynICre}{ }^{+}$mice and was strongest and most uniform in cortical layer $\mathrm{V}$, the base of the cortex, and the $\mathrm{CA} 3$ region, and least consistent in the $\mathrm{CA} 1$ region (Fig. $2 E, F$ ). In $\mathrm{Tscl}^{c^{-}}$SynICre ${ }^{+}$mice, accumulation of X-gal stain in layer $\mathrm{V}$ and at the cortical-white matter border was accompanied by the presence of enlarged, strongly pS6 + cells (Fig. $2 \mathrm{Fa}$ ). In contrast, cells located in the CA1 pyramidal layer demonstrated little or no $\mathrm{X}$-gal staining, as well as low pS6 expression and relatively normal morphology. However, in the stratum oriens above CA1, numerous cells containing the X-gal blue precipitate were enlarged and pS6 positive (Fig. $2 \mathrm{Fb}$ ). In contrast, in controls X-gal blue precipitate was seen in cells of normal size without pS6 staining in the stratum oriens (Fig. $2 E a, E b$ ). These observations indicate that recombination and loss of Tsc1 is not occurring in all neurons, 


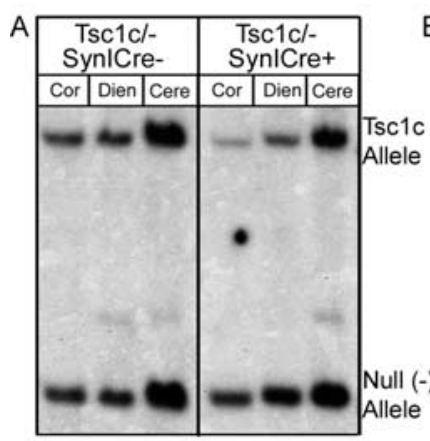

E Tsc1c/w SynlCre+ Phospho-S6/LacZ

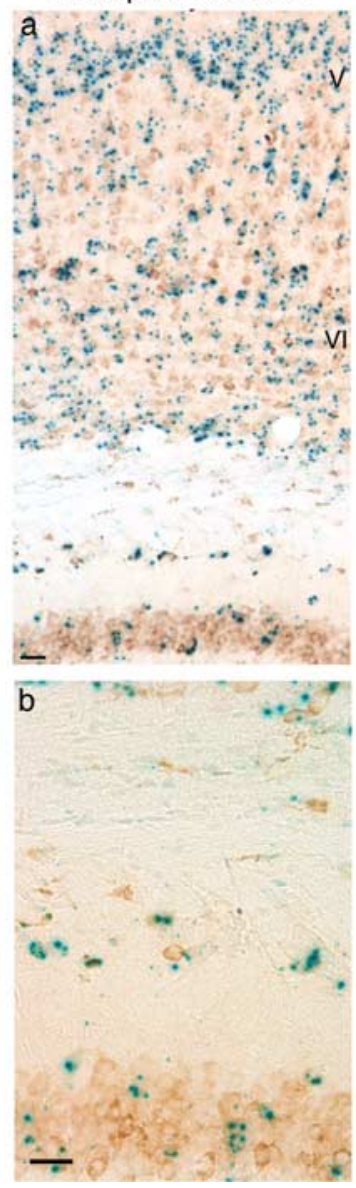

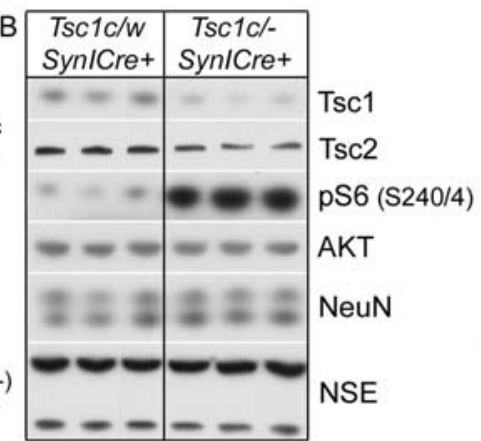

\section{F Tsc1c/-SynlCre+}

Phospho-S6/LacZ
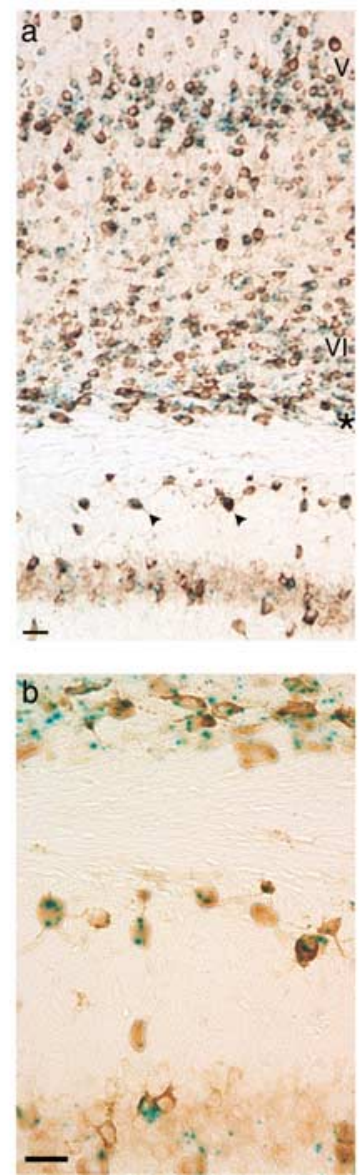

$C_{\text {Tsc1c/w SynlCre+ }}$ Hematoxylin \& Eosin
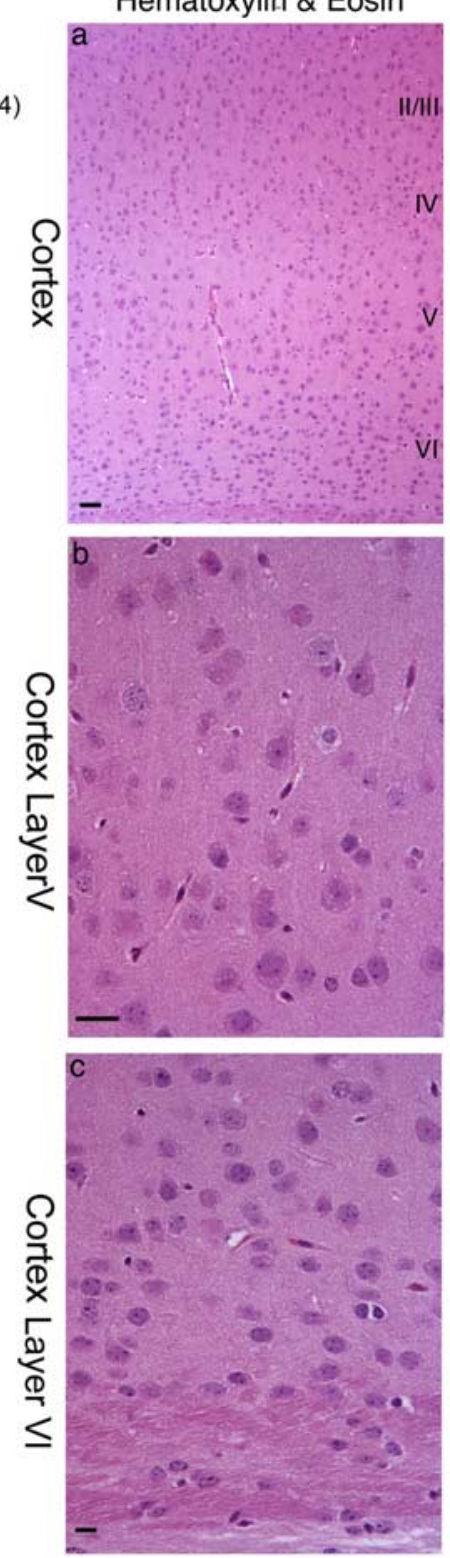

D Tsc1c/- SynlCre+ Hematoxylin \& Eosin
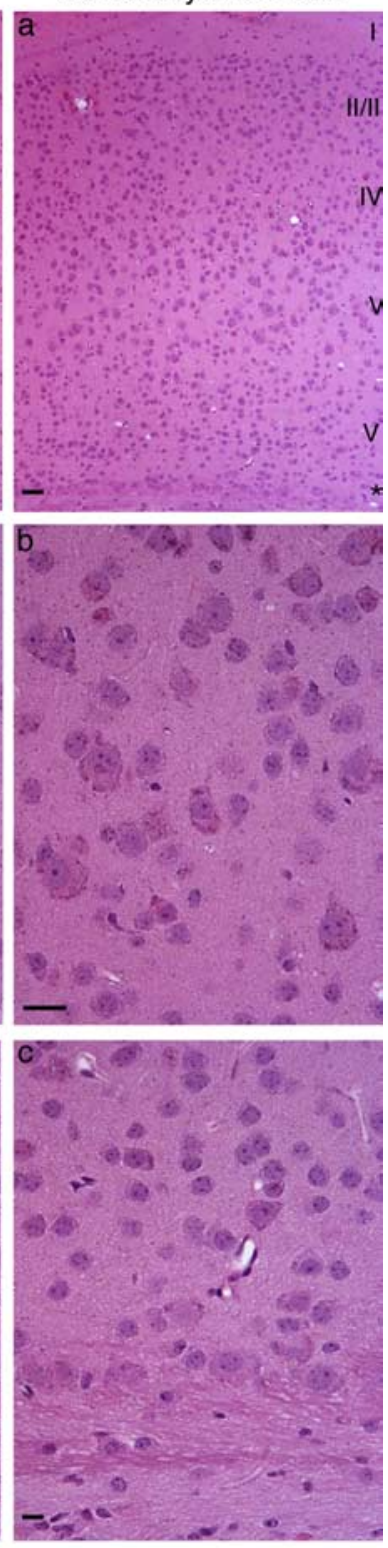

Figure 2. Loss of Tsc1 and brain structural abnormalities in the $\mathrm{Tsc}^{\mathrm{c}-}$ Syn/Cre ${ }^{+}$mice. A, Southern blot analysis demonstrating recombination in brain DNA samples from $\mathrm{Tsc}^{\mathrm{c}-}$ SynlCre compared with $T s c 7^{c-}$ Syn/Cre- mice. The $4.2 \mathrm{~kb}$ (c allele) and $2.4 \mathrm{~kb}$ (- allele) bands are of equal intensity in the $T s c 1^{c^{-}}$Syn/Cre ${ }^{-}$samples, whereas there is a marked shift from the $4.2 \mathrm{~kb}$ to the $2.4 \mathrm{~kb}$ band in the $\mathrm{Tsc}^{\mathrm{C}^{-}} \mathrm{SynI} / \mathrm{Cre}{ }^{+}$samples from cortex (Cor) and diencephalon (Dien) but not cerebellum (Cere). $\boldsymbol{B}$, Immunoblot analysis showing reduction in expression of both tuberin (Tsc2) and hamartin (Tsc1), and elevated pS6 (S240-244) in the brains of $T s c 1^{c_{-}^{-}}$Syn/Cre $e^{+}$mice. AKT is a loading control. NeuN and NSE blots show no difference between $T s c 1^{{ }^{-}}$Syn/Cre ${ }^{+}$and control mice. C, D, Coronal sections from P21 Tsc $7^{\text {ww }}$ SynlCre ${ }^{+}(\boldsymbol{C})$ and $\mathrm{TsC}^{\mathrm{c}^{-}}$Syn/Cre ${ }^{+}(\boldsymbol{D})$ mice stained with H\&E demonstrate an additional layer of cells at the base of the mutant cortex (asterisk) and widespread

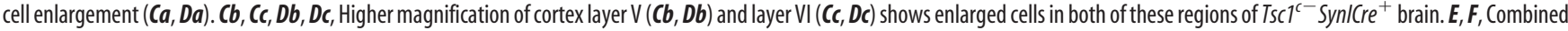

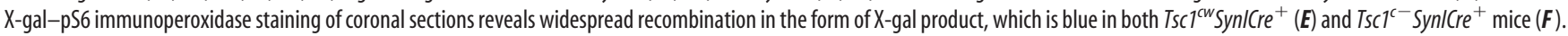
$\mathbf{E a}, \mathbf{F a}$, In contrast to control (Ea), in the $T s c 1^{c-}$ Syn/Cre ${ }^{+}$brain (Fa), enlarged pS6 + cells (brown) in layer V, base of cortex (asterisk), and the stratum oriens (arrowheads) of the hippocampal CA1, associate with the $X$-gal blue precipitate. $\mathbf{E b}, \boldsymbol{F b}$, High-power view of stratum oriens shows a correlation between blue stain indicating cre expression, pS6 positivity, and cell enlargement in Tsc $^{c-}{ }^{-}$Syn/Cre ${ }^{+}$mice. Scale bars: $\mathbf{C a}, \mathbf{D a}, 50 \mu \mathrm{m} ; \boldsymbol{C b}, \mathbf{C c}, \mathbf{D b}, \mathbf{D C}, 25 \mu \mathrm{m} ; \mathbf{E a}, \mathbf{F a}, 20 \mu \mathrm{m} ; \boldsymbol{E b}, \boldsymbol{F b}, 25 \mu \mathrm{m}$.

but rather a major subset, consistent with previous observations using this SynICre allele (Zhu et al., 2001).

\section{mTORC1 activation in enlarged neurons of the neocortex,} hippocampus, and subcortical gray matter

To determine the cellular specificity of Tsc1 loss and subsequent mTORC1 activation, the nature and distribution of the enlarged cells were examined in greater detail. We used neuronal markers NeuN, SMI 311, GAD-67, and the astrocytic marker GFAP, in concert with pS6 and Tsc1, to indicate mTORC1 activation and directly confirm Tsc1 loss. Relatively weak pS6 staining was seen in normal-appearing pyramidal neurons throughout the cortex and subcortical gray matter of the control brain (Fig. $3 A-C, G-I$ ). Intense pS6 reactivity was observed in the majority of enlarged 


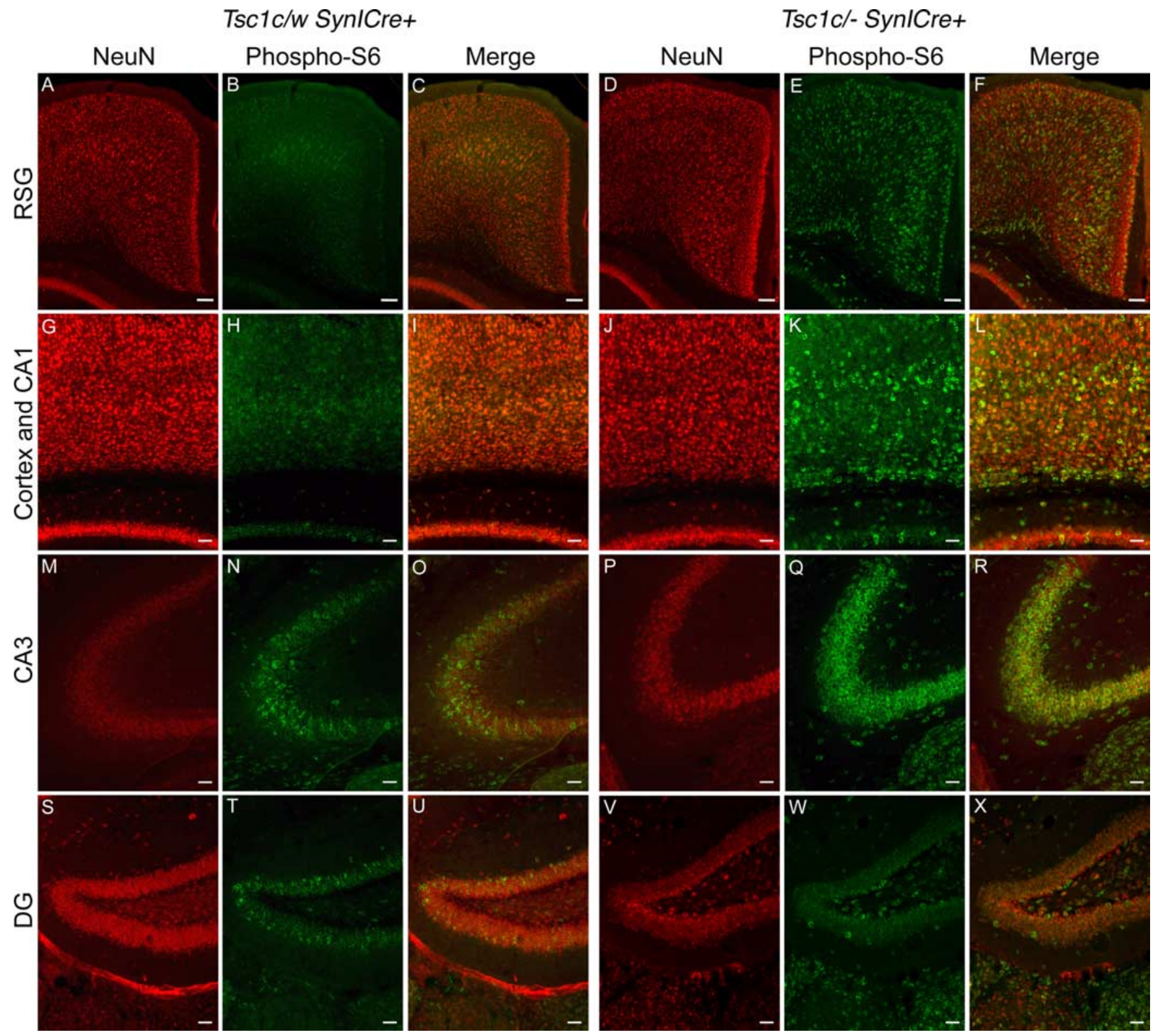

Figure 3. Increased pS6 and widespread architectural abnormalities in P21 $\mathrm{Tsc}^{\mathrm{c}-}$ Syn/Cre ${ }^{+}$mice. $\boldsymbol{A}-\boldsymbol{F}$, In the RSG region of the motor cortex, there is increased pS6 expression in multiple cell

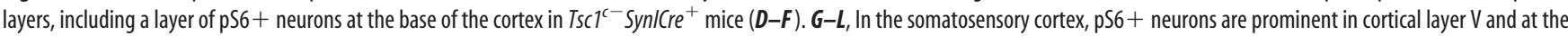
gray-white matter border at the base of the cortex in $T s c 7^{c-}$ Syn/Cre $e^{+}$mice $(J-L)$. Occasional large $\mathrm{p} S 6+$ neurons are seen in the $C A 1$ pyramidal cell layer of the hippocampus but are also seen ectopically in the stratum oriens. $\boldsymbol{M -} \boldsymbol{R}$, In the hippocampal CA3 region, nearly all neurons are pS6+, including those outside the pyramidal cell layer in $T s c 7^{c-}$ Synl(Cre ${ }^{+}$mice $(\boldsymbol{P}-\boldsymbol{R}) . \boldsymbol{S}-\boldsymbol{X}$, In the dentate gyrus, there are occasional enlarged pS6+ cells in the granule cell layer in $\mathrm{Tsc}^{\mathrm{c}-} \mathrm{Syn} / \mathrm{Cre}^{+}(\boldsymbol{V}-\boldsymbol{X})$ mice. However, cells within the hilus are more severely affected, and ectopic $\mathrm{pS6}+$ neurons are also apparent. Scale bars: $A-F, 85 \mu \mathrm{m} ; \boldsymbol{G}-\boldsymbol{X}, 50 \mu \mathrm{m}$.

and ectopic NeuN+ neurons throughout the $\mathrm{Tsc1}^{\mathrm{c}-}$ SynICre ${ }^{+}$ brain. Both motor and sensory cortices were strongly pS6+, with highest expression seen in the pyramidal cell layers (II/III and V), and the extra layer of cells below layer VI (Fig. 3D-F,J-L). Enlarged pyramidal neurons in the $\mathrm{Tscl}^{c-} \mathrm{SynICre}{ }^{+}$mice had also lost expression of Tsc1 (supplemental Fig. 1, compare $D-F$ with $A-C$, available at www.jneurosci.org as supplemental material). Strongly pS6-positive cells of normal size were found in the piriform cortex and the supraoptic nucleus of control brains (data not shown), possibly related to a high level of translational activity in those cells.

pS6 expression was highly variable within the CA1 region of the $T s c 1^{c-}$ SynICre ${ }^{+}$hippocampus. A fraction of CA1 pyramidal neurons were highly pS6+ and enlarged, and those cells were typically seen at the margin of the stratum pyramidale or were ectopically placed in the stratum oriens [Figs. $2 F b, 3$, compare $J-L$ with $G-I$ (control)]. In contrast, nearly all neurons in the CA3 region of the hippocampus were enlarged and pS6+, but similar to the CA1 region, many pS6+ neurons were seen in both the stratum oriens and stratum radiatum [Fig. 3, compare $P-R$ with $M-O$ (control)]. There were occasional large pS6+ neurons in the granule cell layer of the dentate gyrus, but the majority of cells showed weak pS6 staining [Fig. 3, compare $V-X$ with $S-U$ (control)]. However, many strongly pS6+ enlarged neurons were seen in the hilus of the dentate gyrus [Fig. 3, compare $V-X$ with $S-U$ (control)].

We also observed enlarged, strongly pS6+ neurons in many other regions of the $\mathrm{Tscl}^{c^{-}}$SynICre $\mathrm{Cr}^{+}$brains, including thalamus, 
hypothalamus, and the red nucleus of the brainstem (supplemental Fig. 2, available at www.jneurosci.org as supplemental material). In contrast, other subcortical regions were largely unaffected, including caudate and putamen (data not shown). It has recently been noted that $\mathrm{mTORC1}$ activity in the hypothalamus plays a critical role in the regulation of food intake (Cota et al., 2006). The poor weight gain seen in these mice was severe, and although this may have been caused by generalized effects of brain dysfunction, it is possible that overactive mTORC1 in the hypothalamus contributed to reduced food intake.

Interneurons were widely distributed in the $\mathrm{Tsc1}^{c^{-}}$SynICre ${ }^{+}$mouse brain, as assessed by staining for GAD67, a biosynthetic enzyme required for generation of the inhibitory GABA neurotransmitter. These cells were generally pS6+ and enlarged [Fig. 4, compare $D-F$ with $A-C$ (control)]. Many of the ectopic neurons seen in the subcortical white matter (Fig. 4F, asterisk), hippocampal stratum oriens, and dentate hilus (data not shown) were pS6+ GAD67+ interneurons. Tsc1 expression was lost in those GAD67+ cells that were enlarged (supplemental Fig. 1, compare $J-L$ with $G-I$, available at www. jneurosci.org as supplemental material). These observations indicate that both excitatory and inhibitory neurons are affected in this model.

Double labeling for pS6 and GFAP (for mature astrocytes) demonstrated that astrocytes throughout the brain, including hippocampus and cortex, were not enlarged and were not pS6+ in $\mathrm{Tscl}^{c-}$ SynICre ${ }^{+}$mice (Fig. 5D-I). In addition, Tsc1 expression was preserved in astrocytes (supplemental Fig. $1 M-R$, available at www.jneurosci.org as supplemental material). The distribution and degree of GFAP expression was comparable in $\mathrm{Tscl}^{c-}$ SynICre ${ }^{+}$and controls in all brain regions [Fig. 5, compare $D-E$ with $A-C$ (controls)], indicating that there was no reactive astrogliosis in these mice.

These observations indicate that the clinical phenotype of the $\mathrm{Tscl}^{c-}$ SynICre ${ }^{+}$mice was attributable to selective neuronal loss of Tsc1, with no contribution from astrocyte Tsc1 loss or secondary astrogliosis.

\section{Patterns of neuronal dysplasia are seen in $\mathrm{Tscl}^{c-}$ SynICre ${ }^{+}$ mice}

Dysplastic enlarged neurons are a characteristic feature of human TSC tubers, in addition to giant cells (Arseni et al., 1972; Huttenlocher and Heydemann, 1984; Hirose et al., 1995; Crino, 2004; Miyata et al., 2004). Abundant Nissl substance and cytoskeleton abnormalities, such as abnormal cytoplasmic accumulation of argyrophilic fibrils and increased expression of neurofilament proteins, are the most prominent characteristics of dysplastic neurons in cortical tubers (Huttenlocher and Heydemann, 1984; Hirose et al., 1995). To delineate such cells in the Tsc1 ${ }^{c-}$ SynICre ${ }^{+}$ brains, we used expression of nonphosphorylated neurofilament (SMI 311). In control mice, SMI 311 labeled a defined subpopulation of weakly pS6+ pyramidal neurons belonging to cortical layers III, V, and (rarely) nonpyramidal layer VI neurons (Fig. 6A-D) (Ulfig et al., 1998; da Silva et al., 2005). This staining was particularly strong in the retrosplenial granular (RSG) cortex (Fig. 6A-C). In the Tscl ${ }^{c-}$ SynICre ${ }^{+}$brains, nonphosphorylated neurofilament staining was stronger, and nearly all SMI $311+$ neurons were intensely pS6+ (Fig. 6E-G,H). Many SMI $311+$ cells in $\mathrm{Tscl}^{c-}$ SynICre ${ }^{+}$mice demonstrated a clear pyramidal morphology but were larger with thicker dendritic arbors than their counterparts in control mice (Fig. 6, compare $H-I$ with $D$ ). SMI $311+$, pS6+ neurons in the hippocampus demonstrated similar dysplastic features (Fig. $6 \mathrm{~J}$ ). Nissl bodies and filamentous aggregates were also detected in enlarged neurons by thionine and silver staining, most prominently in the brainstem, although rarely in enlarged cortical cells (data not shown). Some of these neurons were aberrantly localized outside the primary pyramidal cell layers, including the molecular layer and subcortical white matter (Fig. 6E-G). These ectopic neurons were isolated and not incorporated into clusters or columns, and some neurons showed abnormal polarity (inverted pyramids) (data not shown). None of these enlarged, pS6+ neurons expressed neuroprogenitor or glial markers, such as nestin or GFAP (data not shown).

To confirm a difference in neuronal cell size, we measured the total soma area of all SMI $311+$ cells in layer V in matched $20 \times$ fields of somatosensory cortex using confocal images from $\mathrm{Tscl}^{c-}$ SynICre ${ }^{+}$and control mice. There was a significant, $60 \%$ increase in soma area in $\mathrm{Tscl}^{c-} \mathrm{SynICre}{ }^{+}$mice compared with age-matched controls ( $p=0.0002$ ) (Fig. $6 \mathrm{~K}$ ). This difference in cell size caused by loss of Tscl clearly parallels the cell enlargement seen in both dysplastic neurons and giant cells of human TSC cortical tubers.

\section{Reduced myelination is seen in $\mathrm{Tscl}^{c-} \mathrm{SynICre}^{+}$mice}

Because hypomyelination is a feature of human TSC lesions (Ridler et al., 2001), we examined myelination in the $\mathrm{Tscl}^{c-}$ SynICre ${ }^{+}$mice. Reduced MBP expression was seen throughout the mutant brain, being most pronounced in the cortex [Fig. 7, compare $D, A$ (control)] and hippocampus [supplemental Fig. 3, compare $F, B$ (control), available at www. 

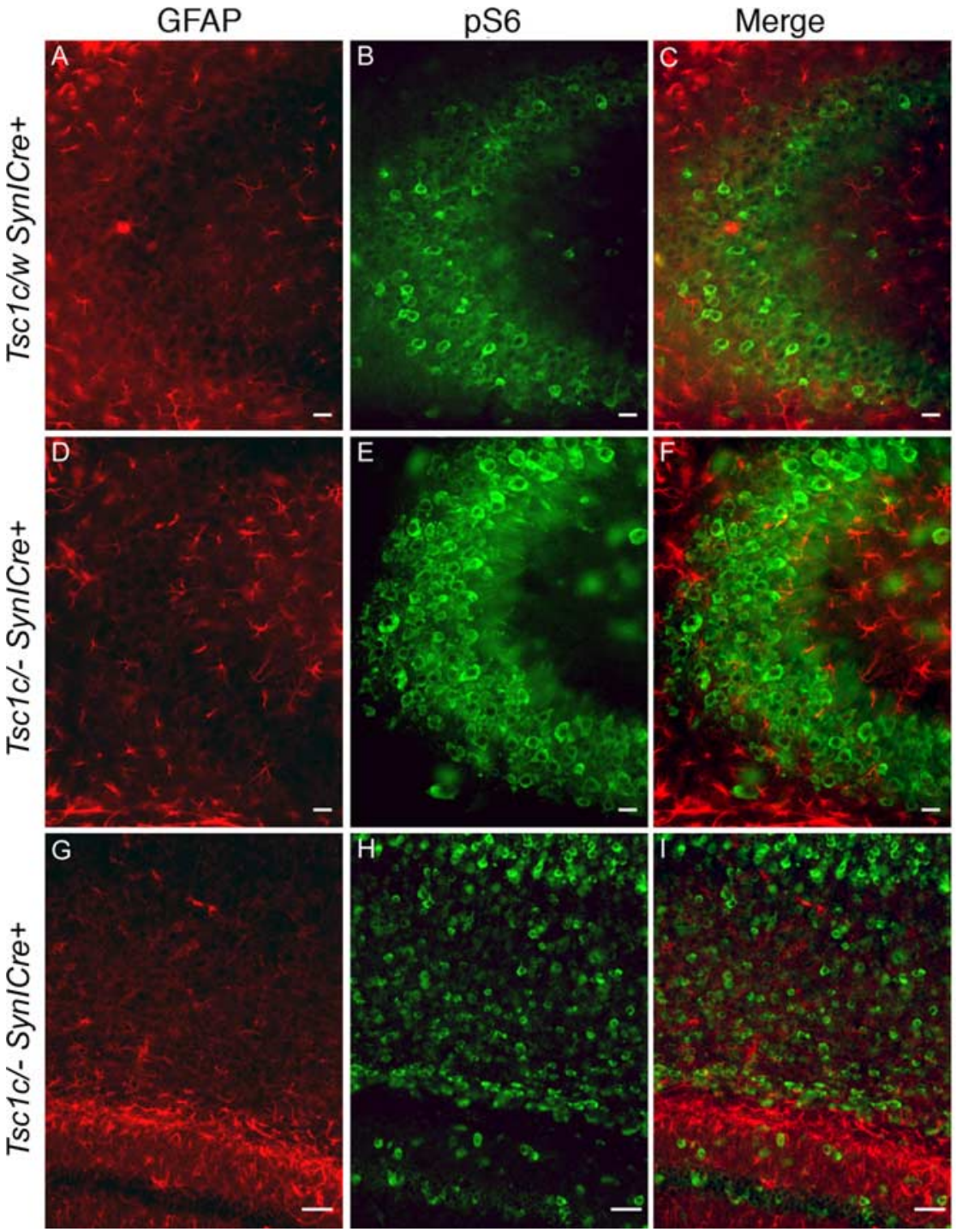

Figure 5. mTORC1 activation resulting from Tsc1 loss is restricted to neurons in $\mathrm{Tsc}^{\mathrm{c}-}$ Syn/(Cre ${ }^{+}$mice. A-F, GFAP-positive astrocytes in the $\mathrm{CA} 3$ region of the hippocampus are distinct from pS6+ neurons in both $\mathrm{P} 21$ control $(\boldsymbol{A}-\boldsymbol{C})$ and $\mathrm{Isc}^{\mathrm{C}-} \mathrm{Synl} / \mathrm{Cre}$ $(\boldsymbol{D}-\boldsymbol{F})$ brains. $\boldsymbol{D}-\boldsymbol{I}$, The number and distribution of GFAP-positive cells in the $\mathrm{Ssc}^{\mathrm{c}}{ }^{-}$Syn/Cre $\mathrm{C}^{+}$hippocampus $(\boldsymbol{D}-\boldsymbol{F})$ and cortex (G-I) shows no evidence for astrogliosis in the mutant brain. Scale bars: $A-F, 20 \mu \mathrm{m} ; \mathbf{G}-\mathbf{I}, 50 \mu \mathrm{m}$.

jneurosci.org as supplemental material], but also seen in the thalamus and hypothalamus (data not shown). There appeared to be a correlation between the increase in pS6 expression in cortical neurons and the regional reduction in myelination [Fig. 7, compare $D-F$ with $A-C$ (control)], suggesting that this effect was caused by neuronal loss of Tsc1. MBP expression was significantly reduced in the $\mathrm{Tscl}^{c-}$ SynICre ${ }^{+}$mice at P7, P14, and P21, demonstrating that there was myelination failure as opposed to a demyelinating process [Fig. 8, compare $D-F$ with $A-C$ (control)].

To determine whether there was a role for oligodendrocyte loss or dysfunction in the myelination deficit, we analyzed immature oligodendrocytes and oligodendrocyte precursors in the cortex and subcortical white matter by staining for galactocerebroside GalC and O4 (Boggs et al., 2004; Polito and Reynolds, 2005)(Fig. 8G-K). In contrast to the MBP deficiency, GalC+ and $\mathrm{O} 4+$ oligodendrocytes were widely distributed throughout the brain and did not differ from control mice (data not shown). Double staining with pS6 and GalC (Fig. $8 G-I$ ) or O4 (Fig. $8 \mathrm{~J}-\mathrm{K}$ )

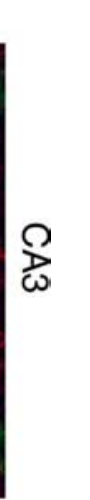

showed that these cells were pS6 negative, suggesting that they were expressing normal levels of Tsc1.

Because oligodendrocyte distribution and number appeared similar in $\mathrm{Tsc1}^{\mathrm{c}-}$ SynICre ${ }^{+}$mice and controls, we examined whether this myelination failure was attributable to an axonal defect. Axons were identified by staining for the NF $160 \mathrm{kDa}$ isoform. Despite the major reduction in myelination in the hippocampus and cortex, axonal projections appeared normal in the $\mathrm{Tscl}^{c-}$ SynICre ${ }^{+}$mice in these regions [supplemental Fig. 3, compare $H, M-P$ with $A-D, I-L$ (controls)].

To examine potential differences in MBP and NF isoform expression in greater detail in the $\mathrm{Tscl}^{c-}$ SynICre ${ }^{+}$ brains, immunoblot analysis of wholebrain homogenates was performed. MBP expression was significantly reduced, and levels of phosphorylated and nonphosphorylated medium chain NF were both increased in $\mathrm{Tscl}^{c-}$ SynICre ${ }^{+}$brains compared with controls (Fig. $8 \mathrm{~L}$ ). Moreover, GAP-43 expression was significantly increased in whole-brain homogenates from the $\mathrm{Tscl}^{c-}$ SynICre ${ }^{+}$mice, compared with controls. Because GAP-43 expression is a marker for active growth cones, these results suggest that the $\mathrm{Tscl}^{\mathrm{c}-}$ SynICre ${ }^{+}$neurons are still actively growing. Thus, these results in aggregate suggest that there is a primary axonal developmental defect caused by loss of Tsc1, which leads to a secondary myelination failure.

\section{Comparison between $\mathrm{Tscl}^{c-}$ SynICre and Tsc1 $^{c c}$ SynICre ${ }^{+}$mice}

We considered the possibility that the phenotype of the $\mathrm{Tscl}^{c-}$ SynICre ${ }^{+}$mice might be more severe than that seen in $\mathrm{Tscl}^{c c} \mathrm{SynICre}{ }^{+}$mice, because of effects of $50 \%$ expression of Tsc1 in all cells, including astrocytes, oligodendrocytes, and neurons in which recombination did not occur. However, clinical features, survival, and brain pathology, including neuronal enlargement, pS6 expression, and lack of myelination, were all indistinguishable in mice of these two genotypes (data not shown). The reduced myelination in the $\mathrm{Tscl}^{c c} \mathrm{SynICre}{ }^{+}$mice provides additional evidence that oligodendrocyte abnormalities do not contribute to this effect.

\section{Discussion}

Here, we have used a Tsc1 floxed allele combined with a Synapsin I promoter-driven Cre allele to eliminate Tsc1 in the majority of differentiating neurons beginning at E13. This novel model provides the opportunity for analysis of the in vivo functions of the Tsc proteins in neuronal development and matches multiple clinical and neuropathological features that are seen in TSC patients. The survival of the mutant mice is markedly compromised, because of poor development with a wasting syndrome, and the mice exhibit spontaneous seizures as well as enhanced 
seizure susceptibility and EEG abnormalities. Furthermore, the brain cytoarchitecture in these mice is highly abnormal. Enlarged, highly pS6+, Tsc1-negative, dysplastic neurons are seen throughout the cortex, hippocampus, and other subcortical gray matter regions, many of which have thickened dendritic arbors and are in ectopic positions. Aberrant cortical lamination is evident throughout the mutant brain, and an additional layer of enlarged pS6 + neurons is present at the base of the cortex. Myelination is also markedly reduced in a pattern indicative of a secondary myelination defect caused by axonal dysfunction resulting from loss of Tsc1 in neurons. It is notable that none of these findings were seen in $T s c 1^{c-}$ mice or in $\mathrm{Tscl}^{c w}$ SynICre ${ }^{+}$mice, which made up most of the controls used in this study. Overall, this model highlights the critical function of the Tsc genes and proteins in neuronal function and development.

Most types of TSC hamartoma, including subependymal giant cell astrocytomas, follow the classic two-hit paradigm for complete loss of tumor suppressor gene function, in which an inherited, germline, inactivated allele is complemented by somatic loss of the second (wild-type) allele in hamartomas (Cheadle et al., 2000; Tucker and Friedman, 2002; Chan et al., 2004). However, the molecular pathogenesis of TSC cortical tubers has been less clear. Despite concerted attempts, loss of heterozygosity for a TSC1 or TSC2 allele has been seen in very few lesions (Tucker and Friedman, 2002). Laser-capture microdissection to isolate tuber giant cells has also failed to provide evidence for twohit pathogenesis, leading to the proposal that alternative genetic events might contribute to tuber development (Han et al., 2004). Nonetheless, much circumstantial evidence points to complete loss of gene function in a subset of cells comprising TSC tubers as key to tuber development. Tuber giant cells have markedly increased expression of pS6 and other markers of mTORC1 activation (Baybis et al., 2004; Miyata et al., 2004). Murine neuroepithelial precursor cells lacking Tsc2 are enlarged and have an aberrant mRNA expression pattern similar to tuber giant cells (Onda et al., 2002). Reduction of Tsc1 or Tsc2 in murine hippocampal slice cultures leads to cell-autonomous enlargement, with extensive abnormalities of the dendritic spines (Tavazoie et al., 2005). The dysplastic, enlarged, and ectopic neurons generated in the current model, in which complete loss of Tscl occurs during neuronal differentiation, provide additional strong support for the two-hit model for tuber pathogenesis.

Although the model we have generated directly tests the function of Tsc1 in neurons in vivo, it is remarkable that the degree of reduction in Tsc2 expression is essentially the same as that seen for Tsc1 (Fig. 2 B). This is consistent with observations on the role of Tsc1 as a critical binding partner of Tsc2 that prevents its degradation (Benvenuto et al., 2000; Chong-Kopera et al., 2006). Thus, it is likely that loss of Tsc1 and loss of Tsc2 have equivalent
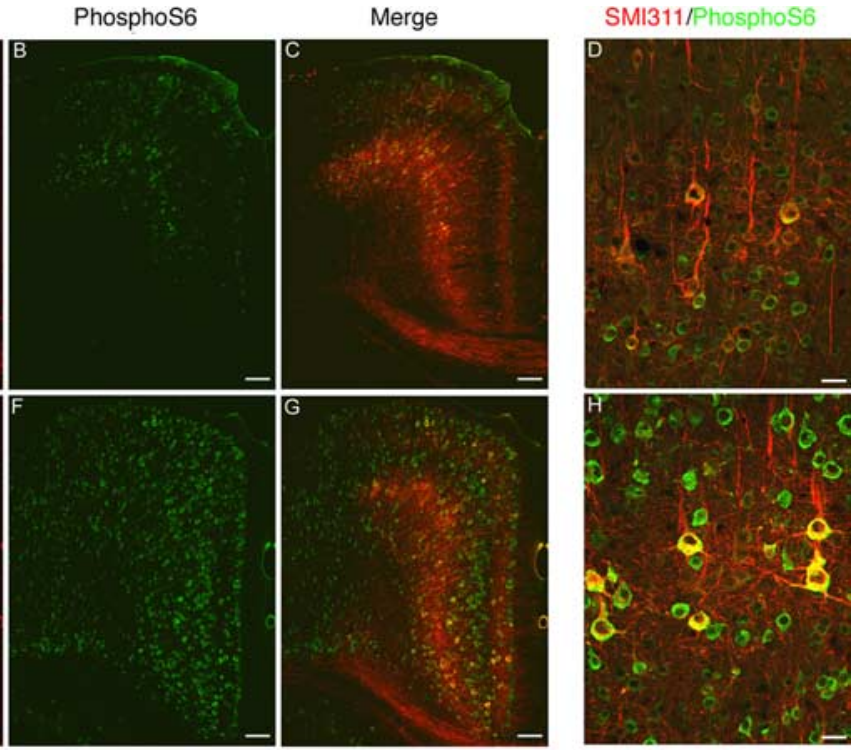

SMI311/PhosphoS6

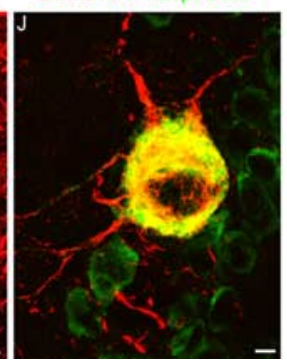

$\mathrm{K}$

Cell size as determined by SMI311 staining

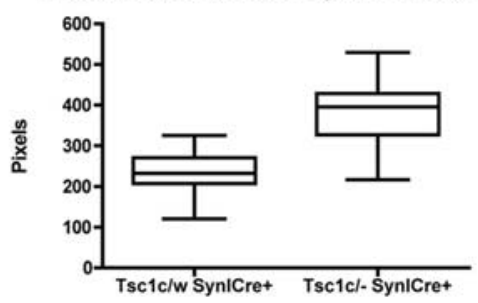

Figure 6. Enlarged, dysplastic pyramidal neurons in $\mathrm{TsC}^{\mathrm{c}-}$ Syn/Cre ${ }^{+}$brains. $\boldsymbol{A}-\boldsymbol{C}, \boldsymbol{E}-\mathbf{G}$, In the RSG region of the motor cortex the majority of pyramidal neurons identified by SMI 311 staining in layers V and III are strongly pS6 + in P21 $\mathrm{TsCl}^{\mathrm{c}-} \mathrm{Syn}_{\mathrm{C}} \mathrm{Cre}^{+}$ mice, in contrast to controls (A-C).E-G, Disruption of normal cortical lamination in $\mathrm{TsCl}^{c-}$ Syn/Cre ${ }^{+}$mice is also evident, and 3.2-3.4 mm lateral to midline) shows increased soma size in $\mathrm{ScC}^{\mathrm{c}-}$ Syn/Cre ${ }^{+}$mice when compared with controls ( $p=$ 0.0002). Scale bars: $\boldsymbol{A}-\boldsymbol{C}, \boldsymbol{E}-\mathbf{G}, 100 \mu \mathrm{m} ; \boldsymbol{D}, \boldsymbol{H}, 25 \mu \mathrm{m} ; \boldsymbol{I}, \boldsymbol{J}, 10 \mu \mathrm{m}$.

effects on mTORC1 and other signaling abnormalities leading to aberrant neuronal development.

The clinical and neuropathologic phenotype of the $\mathrm{Tscl}^{c-}$ SynICre ${ }^{+}$mice has several important similarities to that observed in human TSC patients. Cortex and hippocampus are significantly affected, with many enlarged pS6+ dysplastic neurons, as well as hypomyelination. Other areas with abnormal cytoarchitecture include the red nucleus, and these changes are likely to contribute to the abnormal tone (clasping) and tremor observed in these mice. The mice display a high incidence of stimulation-evoked and spontaneous seizures. Because the majority of neurons are affected by the mutation, there is widespread disruption of laminar organization in cortex and hippocampus, and both interictal and ictal EEG show lack of substantial synchrony. Although most neurons undergo recombination and loss of Tsc1, the mixture of $T s c 1^{c-}$ and pS6+ neurons is similar to the mixture of cell types present in TSC cortical tubers.

The $\mathrm{Tsc1}^{c-}$ SynICre ${ }^{+}$mice demonstrated an early-onset seizure disorder, which appeared in many cases to cause the death of older animals. In contrast to previous suggestions that seizures in TSC might be related to astrocyte dysfunction consequent to loss of Tsc1/Tsc2 (Uhlmann et al., 2002; Wong et al., 2003), these 

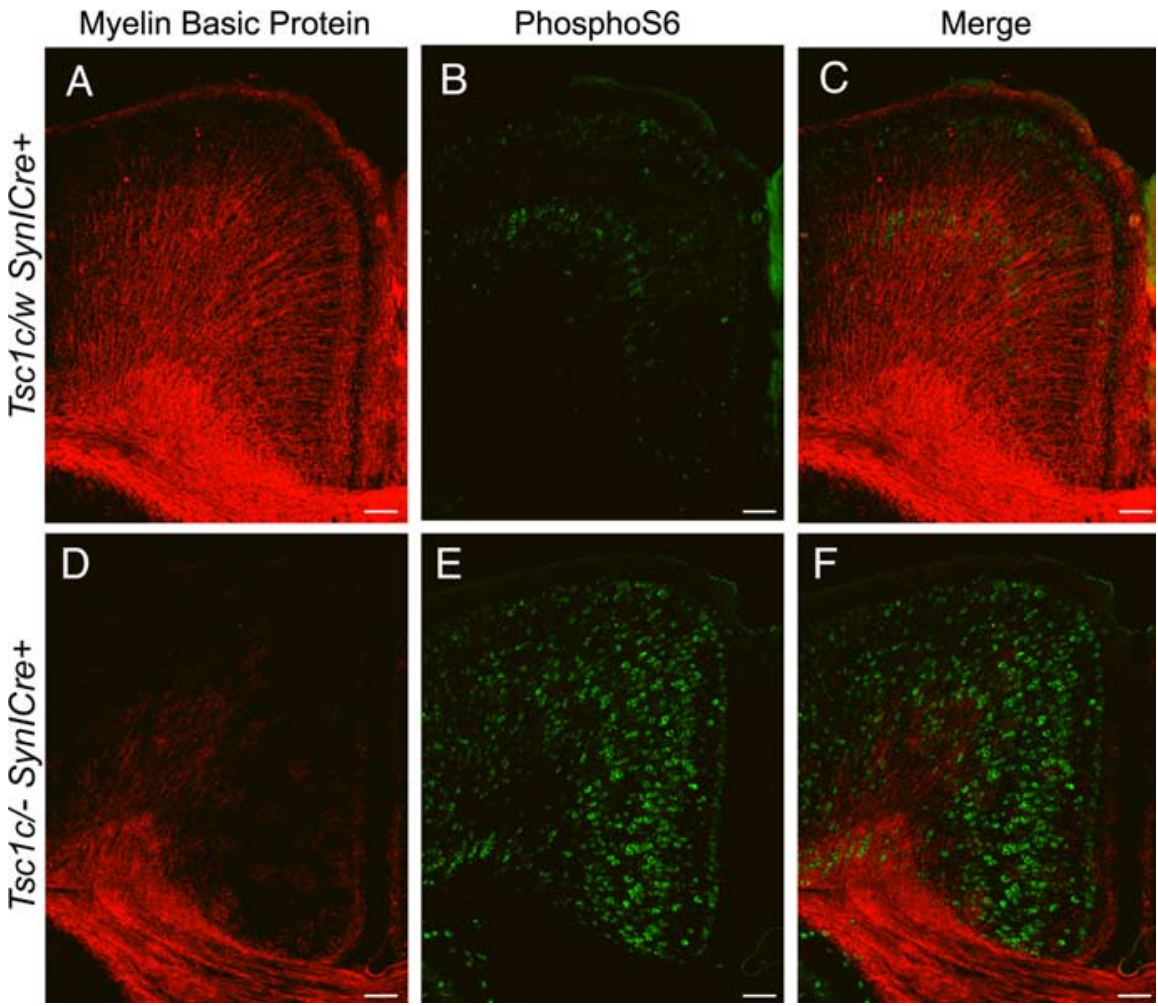

Figure 7. Hypomyelination in $T s c 1^{c-}$ Syn/Cre ${ }^{+}$brains. $\boldsymbol{A}-\boldsymbol{F}$, Compared with controls $(\boldsymbol{A}-\boldsymbol{C})$, the RSG region of motor cortex of $\mathrm{TsC}^{\mathrm{C}}{ }^{-}$Syn/ $\mathrm{Cre} \mathrm{C}^{+}$brains shows a marked reduction in MBP expression $(\boldsymbol{D}-\boldsymbol{F})$ in the corpus callosum, the pericallosal white matter, and radiating fibers extending into the cerebral cortex. Scale bars, $100 \mu \mathrm{m}$.

observations establish that neuronal loss of Tsc1/Tsc2 leads to clinically important seizure predisposition. These in vivo findings are consistent with previous in vitro data demonstrating that loss of Tsc1 and Tsc2 in neurons leads to enhanced glutamatergic neurotransmission (Tavazoie et al., 2005).

Enlarged multinucleated giant cells, such as those seen in TSC cortical tubers, are not seen in these mice. We suspect that this is because of the timing of loss of Tsc1 in this model, with cremediated recombination occurring at the beginning of neuronal differentiation (E12.5) (Zhu et al., 2001) (data not shown) and loss of Tsc1 protein following thereafter. Indeed, loss of Tsc1 engineered through use of a nestin promoter-driven cre in neuroepithelial progenitor cells, as early as E8.5, leads to mice with markedly enlarged "giant" cells in the cortex and hippocampus (H. Onda and D. J. Kwiatkowski, unpublished observations), consistent with an important developmental effect of loss of Tsc1. Others have also proposed that second hit events occur in TSC patients at earlier time points in brain development to lead to generation of giant cells (Ess et al., 2005). A previously described Tsc mouse model, in which the $T s c 1^{c}$ allele was combined with a GFAP-cre allele, also had a pronounced seizure phenotype, shortened survival (although much longer than seen here), generalized astrogliosis, and hippocampal neuronal abnormalities (Uhlmann et al., 2002; Wong et al., 2003; Ess et al., 2004). However, cortical neuronal abnormalities were not seen in those mice, and it was not clear whether the seizure predisposition was attributable to astrocytic or hippocampal neuronal loss of Tsc1. Nonetheless, both neurons and astrocytes are abnormal in TSC tubers, and likely both contribute to epileptogenesis.

Cortical tubers occur as multiple, discrete supratentorial gray matter lesions in which normal cortical lamination is disrupted. In contrast, the $\mathrm{Tscl}^{c-} \mathrm{SynICre}{ }^{+}$mouse brain is more diffusely affected both cortically and subcortically. Changes in cortical lamination were delineated by analysis of NeuN and pS6 expression in the $\mathrm{Tscl}^{c-}$ SynICre ${ }^{+}$mice, demonstrating an additional layer of enlarged pS6+ neurons at the base of the cortex. It is possible that these cells are residual subplate cells that have failed to undergo apoptosis, as they are seen in control brains at P7. However, aberrantly positioned ("ectopic") cells were widespread in the white matter and hippocampus, suggesting that neuronal migration was more generally perturbed in these mice because of loss of Tsc1. This phenomenon may be related to cytoskeletal abnormalities in Tsc1-deficient neurons, including abnormal neurofilament expression (Fig. $8 L$ ) and elevated levels of phospho-cofilin (Tavazoie et al., 2005).

Myelination defects are commonly observed in the TSC brain, both focally within tubers and more diffusely (Ridler et al., 2001; Zikou et al., 2005). However, it has been unclear whether the defect in myelination is a cell-autonomous defect caused by loss of TSC function in oligodendrocytes or indirect as a result of neuronal dysfunction. Previous studies have indicated that in the adult CNS, myelin and growth-associated protein GAP-43 have an inverse regional distribution (Kapfhammer and Schwab, 1994). Furthermore, after suppression of myelination by $\mathrm{X}$-irradiation of the spinal cord, GAP-43 is upregulated. These experiments have led to the hypothesis that myelin-associated inhibitors stabilize neuronal growth and limit plasticity in the adult CNS. Although the effect of oligodendrocyte-derived inhibitors on neurons is well established, less is known about the effect of neurons on oligodendrocyte development. Accumulating evidence suggests that neuron-derived factors can regulate oligodendrocyte development at multiple stages, such as proliferation, survival, differentiation, and formation of myelin (Barres and Raff, 1999; Simons and Trajkovic, 2006). Thus, there appears to be mutual regulation of neurons and oligodendrocytes that is required for proper myelination and effective neuronal function.

Striking myelination delay was seen in the $\mathrm{Tscl}^{\mathrm{c}-} \mathrm{SynICre}$ mice from P7 through P21. GAP-43, which is normally expressed during axonal outgrowth before P7 (Erzurumlu et al., 1990), was highly expressed in P21 Tsc1c-SynICre ${ }^{+}$mice suggesting that axons are in a persistent growth-enabled state because of the loss of Tsc1 (Benowitz and Routtenberg, 1997). The normal distribution of premyelinating oligodendrocytes and their lack of pS6 expression suggest that oligodendrocytes have normal levels of Tscl and are not directly affected in this model. Rather, it appears that loss of Tsc1 in neurons causes a lack of induction of myelination, consistent with an important developmental role of interaction between neurons and oligodendrocytes (Boiko and Winckler, 2006). It is not clear whether loss of Tsc1 leads to abnormal expression of neuronal signaling molecules that can regulate oligodendrocyte development. Alternatively, loss of Tscl can interfere with intracellular signaling pathways such as those regulating rho GTPases. Many axon guidance molecules 
such as Semaphorin 3A and myelinassociated inhibitors, including Nogo, reduce axonal growth cone extension in a signaling pathway that involves rhoA, ROCK, and LIM kinase, and leads to phosphorylation of cofilin at S3 (Wu et al., 2005; Hsieh et al., 2006). The recent observation that pS3-cofilin levels are increased in single neurons lacking Tsc1 (Tavazoie et al., 2005) and evidence of an interaction between Tsc1/Tsc2 and rho (Lamb et al., 2000; Astrinidis et al., 2002; Goncharova et al., 2004) suggest that alterations in rho activation in neurons lacking Tsc1 may lead to growth cone developmental abnormalities causing this myelination defect. Experiments investigating the role of Tsc proteins in the neuron-oligodendrocyte interaction using cocultures systems are underway and may shed light into the mechanisms of myelination in the CNS.

Neuron-specific deletion of Tsc1 provides a novel model to study the in vivo functions of the Tsc proteins in neuronal development and indicates that Tsc1/2 complex is critical for cell size, migration, neuritic outgrowth, and myelination in the developing brain. Based on previous in vitro studies, activation of the translational machinery via mTORC1 is likely to underlie many of the functions of TSC complex in this model, suggesting that the developmental defects observed in these mice may be reversible by inhibition of mTORC1 using rapamycin and its analogs. Treatment of $T s c 1^{c-}$ SynICre mice with rapamycin during different periods of development can provide critical preclinical data for use of rapamycin in TSC patients and also provide insights as to how and when the TSC/mTORC1 pathway and the associated translational machinery is involved in neuronal developmental processes such as cell size regulation, migration, axonal and dendritic arborization, and myelination.

Note added in proof. In simultaneous studies performed on mice of this same genotype (founders provided by us), Wang et al. (2007) have recently reported on multiple aspects of histopathology, brain anatomy, and electrical activity in $T s c 1^{c c}$ SynICre ${ }^{+}$mice. In general, their findings are consistent with those reported here. However, they did not perform double labeling of brain sections with antibodies against pS6 and a variety of cellspecific markers, and we suspect that this accounts for their failure to observe the abnormalities of cortical organization and ectopic neurons that we have noted. In addition, Wang et al. (2007) did not find differences in the size of SMI $311+$ neurons in mutant mice compared with controls in a two-dimensional study of

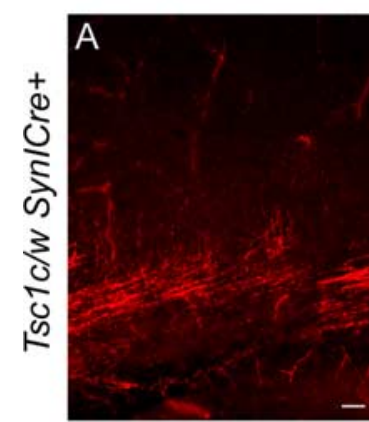

P14
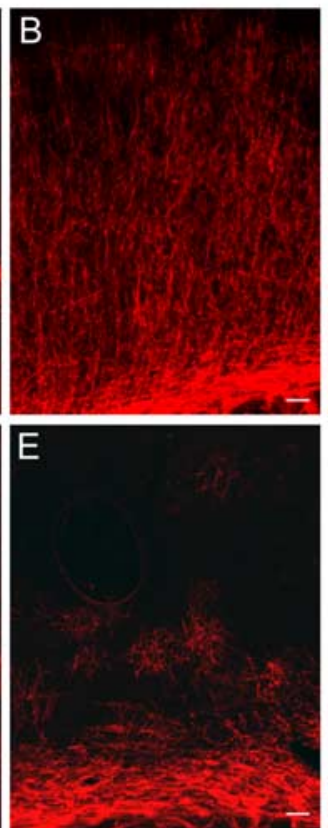

Phosphos6

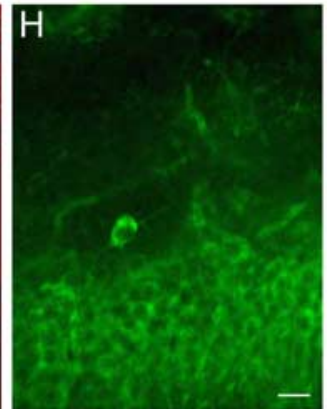

O4/Phosphos6
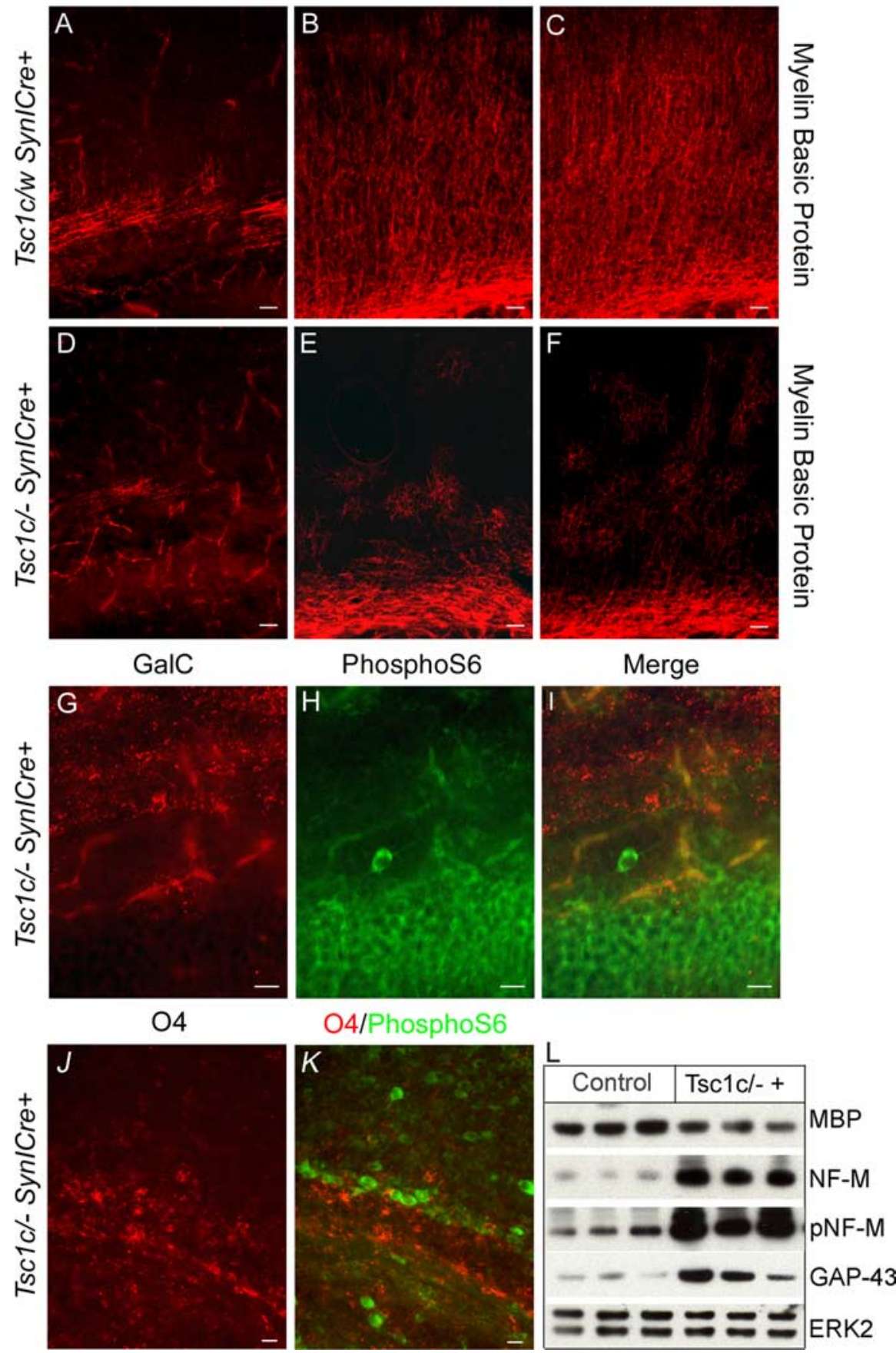

Figure 8. Developmental analysis of MBP expression, oligodendrocyte distribution and differential expression of neuronal proteins in $\mathrm{TsC}^{\mathrm{c}-}$ SynlCre ${ }^{+}$mice. $\boldsymbol{A}-\boldsymbol{F}, \mathrm{MBP}$ expression (red) is reduced at P7, P14, and P21 in the external capsule of $\mathrm{TsCl}^{\mathrm{c}-}$ SynICre ${ }^{+}$cortex $(\boldsymbol{D}-\boldsymbol{F})$ compared with controls $(\boldsymbol{A}-\boldsymbol{C})$. A persistent immature patchy pattern of MBP expression is seen throughout development in the mutant cortex. G-K, Premyelinating oligodendrocytes, as assessed by GalC (red; G, I) and 04 (red;

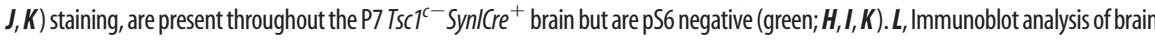
lysates shows that MBP levels are reduced in $\mathrm{SsC}^{C^{-}}$Syn/ $\mathrm{Cre}^{+}$brains, whereas levels of nonphosphorylated and phosphorylated medium chain neurofilament and GAP-43 are increased, compared with controls. Scale bars: $A-F, 50 \mu \mathrm{m} ; \mathbf{G}-K, 20 \mu \mathrm{m}$.

randomly sampled neurons. This difference from the present study may be attributable to the fact that we sampled a population of SMI 311+ neurons in layer V of neocortex, in which neuronal size is homogeneous in controls. In addition, our use of $50 \mu \mathrm{m}$ sections and confocal fluorescence microscopy (in contrast to Wang et al., 2007) may have afforded better quantitation of these differences. 


\section{References}

Arseni C, Alexianu M, Horvat L, Alexianu D, Petrovici A (1972) Fine structure of atypical cells in tuberous sclerosis. Acta Neuropathol (Berl) 21:185-193.

Astrinidis A, Henske EP (2005) Tuberous sclerosis complex: linking growth energy signaling pathways with human disease. Oncogene 24:7475-7481.

Astrinidis A, Cash TP, Hunter DS, Walker CL, Chernoff J, Henske EP (2002) Tuberin, the tuberous sclerosis complex 2 tumor suppressor gene product, regulates Rho activation, cell adhesion and migration. Oncogene 21:8470-8476.

Barres BA, Raff MC (1999) Axonal control of oligodendrocyte development. J Cell Biol 147:1123-1128.

Baybis M, Yu J, Lee A, Golden JA, Weiner H, McKhann G, Aronica E, Crino PB (2004) mTOR cascade activation distinguishes tubers from focal cortical dysplasia. Ann Neurol 56:478-487.

Benowitz LI, Routtenberg A (1997) GAP-43: an intrinsic determinant of neuronal development plasticity. Trends Neurosci 20:84-91.

Benvenuto G, Li S, Brown SJ, Braverman R, Vass WC, Cheadle JP, Halley DJ, Sampson JR, Wienecke R, DeClue JE (2000) The tuberous sclerosis-1 (TSC1) gene product hamartin suppresses cell growth and augments the expression of the TSC2 product tuberin by inhibiting its ubiquitination. Oncogene 19:6306-6316.

Boggs JM, Wang H, Gao W, Arvanitis DN, Gong Y, Min W (2004) A glycosynapse in myelin? Glycoconj J 21:97-110.

Boiko T, Winckler B (2006) Myelin under construction-teamwork required. J Cell Biol 172:799-801.

Chan JA, Zhang H, Roberts PS, Jozwiak S, Wieslawa G, Lewin-Kowalik J, Kotulska K, Kwiatkowski DJ (2004) Pathogenesis of tuberous sclerosis subependymal giant cell astrocytomas: biallelic inactivation of TSC1 or TSC2 leads to mTOR activation. J Neuropath Exp Neurol 63:1236-1242.

Cheadle JP, Reeve MP, Sampson JR, Kwiatkowski DJ (2000) Molecular genetic advances in tuberous sclerosis. Hum Genet 107:97-114.

Chong-Kopera H, Inoki K, Li Y, Zhu T, Garcia-Gonzalo FR, Rosa JL, Guan KL (2006) TSC1 stabilizes TSC2 by inhibiting the interaction between TSC2 the HERC1 ubiquitin ligase. J Biol Chem 281:8313-8316.

Cota D, Proulx K, Smith KA, Kozma SC, Thomas G, Woods SC, Seeley RJ (2006) Hypothalamic mTOR signaling regulates food intake. Science 312:927-930.

Crino PB (2004) Molecular pathogenesis of tuber formation in tuberous sclerosis complex. J Child Neurol 19:716-725.

Curatolo P (2003) Tuberous sclerosis complex: from basic science to clinical phenotypes. Cambridge, UK: Mac Keith.

da Silva AV, Regondi MC, Cavalheiro EA, Spreafico R (2005) Disruption of cortical development as a consequence of repetitive pilocarpine-induced status epilepticus in rats. Epilepsia 46 [Suppl 5]:22-30.

de Vries P, Humphrey A, McCartney D, Prather P, Bolton P, Hunt A (2005) Consensus clinical guidelines for the assessment of cognitive behavioural problems in tuberous sclerosis. Eur Child Adolesc Psychiatry 14:183-190.

DiMario FJ (2004) Brain abnormalities in tuberous sclerosis complex. J Child Neurol 19:650-657.

El-Hashemite N, Zhang H, Henske EP, Kwiatkowski DJ (2003) Mutation in TSC2 activation of mammalian target of rapamycin signalling pathway in renal angiomyolipoma. Lancet 361:1348-1349.

Erzurumlu RS, Jhaveri S, Benowitz LI (1990) Transient patterns of GAP-43 expression during the formation of barrels in the rat somatosensory cortex. J Comp Neurol 292:443-456.

Ess KC, Uhlmann EJ, Li W, Li H, Declue JE, Crino PB, Gutmann DH (2004) Expression profiling in tuberous sclerosis complex (TSC) knockout mouse astrocytes to characterize human TSC brain pathology. Glia 46:28-40.

Ess KC, Kamp CA, Tu BP, Gutmann DH (2005) Developmental origin of subependymal giant cell astrocytoma in tuberous sclerosis complex. Neurology 64:1446-1449.

Gomez M, Sampson J, Whittemore V (1999) The tuberous sclerosis complex. Oxford: Oxford UP.

Goncharova E, Goncharov D, Noonan D, Krymskaya VP (2004) TSC2 modulates actin cytoskeleton and focal adhesion through TSC1-binding domain and the Rac1 GTPase. J Cell Biol 167:1171-1182.

Goncharova EA, Goncharov DA, Eszterhas A, Hunter DS, Glassberg MK, Yeung RS, Walker CL, Noonan D, Kwiatkowski DJ, Chou MM, Panettieri RA, Krymskaya VP (2002) Tuberin regulates p70 S6 kinase activation and ribosomal protein S6 phosphorylation: a role for the TSC2 tumor suppressor gene in pulmonary lymphangioleiomyomatosis (LAM). J Biol Chem 277:30958-30967.

Han S, Santos TM, Puga A, Roy J, Thiele EA, McCollin M, StemmerRachamimov A, Ramesh V (2004) Phosphorylation of tuberin as a novel mechanism for somatic inactivation of the tuberous sclerosis complex proteins in brain lesions. Cancer Res 64:812-816.

Hirose T, Scheithauer BW, Lopes MB, Gerber HA, Altermatt HJ, Hukee MJ, VandenBerg SR, Charlesworth JC (1995) Tuber and subependymal giant cell astrocytoma associated with tuberous sclerosis: an immunohistochemical, ultrastructural, and immunoelectron and microscopic study. Acta Neuropathol (Berl) 90:387-399.

Holz MK, Ballif BA, Gygi SP, Blenis J (2005) mTOR and S6K1 mediate assembly of the translation preinitiation complex through dynamic protein interchange and ordered phosphorylation events. Cell 123:569-580.

Hsieh SH, Ferraro GB, Fournier AE (2006) Myelin-associated inhibitors regulate cofilin phosphorylation neuronal inhibition through LIM kinase slingshot phosphatase. J Neurosci 26:1006-1015.

Huttenlocher PR, Heydemann PT (1984) Fine structure of cortical tubers in tuberous sclerosis: a Golgi study. Ann Neurol 16:595-602.

Inoki K, Corradetti MN, Guan KL (2005) Dysregulation of the TSC-mTOR pathway in human disease. Nat Genet 37:19-24.

Ives JR (2005) New chronic EEG electrode for critical/intensive care unit monitoring. J Clin Neurophysiol 22:119-123.

Kapfhammer JP, Schwab ME (1994) Inverse patterns of myelination and GAP-43 expression in the adult CNS: neurite growth inhibitors as regulators of neuronal plasticity? J Comp Neurol 340:194-206.

Kwiatkowski DJ (2003) Tuberous sclerosis: from tubers to mTOR. Ann Hum Genet 67:87-96.

Kwiatkowski DJ, Manning BD (2005) Tuberous sclerosis: a GAP at the crossroads of multiple signaling pathways. Hum Mol Genet 14 [Suppl 2]:R251-R258.

Kwiatkowski DJ, Zhang H, Bandura JL, Heiberger KM, Glogauer M, elHashemite N, Onda H (2002) A mouse model of TSC1 reveals sexdependent lethality from liver hemangiomas, and up-regulation of p70S6 kinase activity in Tsc1 null cells. Hum Mol Genet 11:525-534.

Lamb RF, Roy C, Diefenbach TJ, Vinters HV, Johnson MW, Jay DG, Hall A (2000) The TSC1 tumour suppressor hamartin regulates cell adhesion through ERM proteins and the GTPase Rho. Nat Cell Biol 2:281-287.

Mao X, Fujiwara Y, Orkin SH (1999) Improved reporter strain for monitoring Cre recombinase-mediated DNA excisions in mice. Proc Natl Acad Sci USA 96:5037-5042.

Meikle L, McMullen JR, Sherwood MC, Lader AS, Walker V, Chan JA, Kwiatkowski DJ (2005) A mouse model of cardiac rhabdomyoma generated by loss of Tsc1 in ventricular myocytes. Hum Mol Genet 14:429-435.

Miyata H, Chiang AC, Vinters HV (2004) Insulin signaling pathways in cortical dysplasia TSC-tubers: tissue microarray analysis. Ann Neurol 56:510-519.

Niida Y, Stemmer-Rachamimov AO, Logrip M, Tapon D, Perez R, Kwiatkowski DJ, Sims K, MacCollin M, Louis DN, Ramesh V (2001) Survey of somatic mutations in tuberous sclerosis complex (TSC) hamartomas suggests different genetic mechanisms for pathogenesis of TSC lesions. Am J Hum Genet 69:493-503.

Onda H, Crino PB, Zhang H, Murphey RD, Rastelli L, Gould Rothberg BE, Kwiatkowski DJ (2002) Tsc2 null murine neuroepithelial cells are a model for human tuber giant cells, and show activation of an mTOR pathway. Mol Cell Neurosci 21:561-574.

Polito A, Reynolds R (2005) NG2-expressing cells as oligodendrocyte progenitors in the normal and demyelinated adult central nervous system. J Anat 207:707-716.

Ridler K, Bullmore ET, De Vries PJ, Suckling J, Barker GJ, Meara SJ, Williams SC, Bolton PF (2001) Widespread anatomical abnormalities of grey white matter structure in tuberous sclerosis. Psychol Med 31:1437-1446.

Sarbassov DD, Ali SM, Sabatini DM (2005) Growing roles for the mTOR pathway. Curr Opin Cell Biol 17:596-603.

Scheithauer BW, Reagan TJ (1999) Neuropathology. In: Tuberous sclerosis complex (Gomez MR, ed) pp 101-144. New York, Oxford UP.

Schmued LC, Stowers CC, Scallet AC, Xu L (2005) Fluoro-Jade C results in ultra high resolution contrast labeling of degenerating neurons. Brain Res 1035:24-31.

Simons M, Trajkovic K (2006) Neuron-glia communication in the control of oligodendrocyte function and myelin biogenesis. J Cell Sci 119:4381-4389. 
Talos DM, Fishman RE, Park H, Folkerth RD, Follett PL, Volpe JJ, Jensen FE (2006) Developmental regulation of alpha-amino-3-hydroxy-5-methyl4-isoxazole-propionic acid receptor subunit expression in forebrain and relationship to regional susceptibility to hypoxic/ischemic injury. I. Rodent cerebral white matter cortex. J Comp Neurol 497:42-60.

Tavazoie SF, Alvarez VA, Ridenour DA, Kwiatkowski DJ, Sabatini BL (2005) Regulation of neuronal morphology function by the tumor suppressors Tsc1 and Tsc2. Nat Neurosci 8:1727-1734.

Tee AR, Blenis J (2005) mTOR, translational control and human disease. Semin Cell Dev Biol 16:29-37.

Thiele EA (2004) Managing epilepsy in tuberous sclerosis complex. J Child Neurol 19:680-686.

Tucker T, Friedman JM (2002) Pathogenesis of hereditary tumors: beyond the "two-hit" hypothesis. Clin Genet 62:345-357.

Uhlmann EJ, Wong M, Baldwin RL, Bajenaru ML, Onda H, Kwiatkowski DJ, Yamada K, Gutmann DH (2002) Astrocyte-specific TSC1 conditional knockout mice exhibit abnormal neuronal organization and seizures. Ann Neurol 52:285-296.

Ulfig N, Nickel J, Bohl J (1998) Monoclonal antibodies SMI 311 and SMI 312 as tools to investigate the maturation of nerve cells and axonal patterns in human fetal brain. Cell Tissue Res 291:433-443.

Wang Y, Greenwood JS, Calcagnotto ME, Kirsch HE, Barbaro NM, Baraban SC (2007) Neocortical hyperexcitability in a human case of tuberous sclerosis complex and mice lacking neuronal expression of TSC1. Ann Neurol 61:139-152.

Wenzel HJ, Patel LS, Robbins CA, Emmi A, Yeung RS, Schwartzkroin PA (2004) Morphology of cerebral lesions in the Eker rat model of tuberous sclerosis. Acta Neuropathol (Berl) 108:97-108.

Wiznitzer M (2004) Autism and tuberous sclerosis. J Child Neurol 19:675-679.

Wong M, Ess KC, Uhlmann EJ, Jansen LA, Li W, Crino PB, Mennerick S, Yamada KA, Gutmann DH (2003) Impaired glial glutamate transport in a mouse tuberous sclerosis epilepsy model. Ann Neurol 54:251-256.

Wu KY, Hengst U, Cox LJ, Macosko EZ, Jeromin A, Urquhart ER, Jaffrey SR (2005) Local translation of RhoA regulates growth cone collapse. Nature 436:1020-1024.

Yeung RS, Katsetos CD, Klein-Szanto A (1997) Subependymal astrocytic hamartomas in the Eker rat model of tuberous sclerosis. Am J Pathol 151:1477-1486.

Zhu Y, Romero MI, Ghosh P, Ye Z, Charnay P, Rushing EJ, Marth JD, Parada LF (2001) Ablation of NF1 function in neurons induces abnormal development of cerebral cortex and reactive gliosis in the brain. Genes Dev 15:859-876.

Zikou A, Ioannidou MC, Tzoufi M, Astrakas L, Argyropoulou MI (2005) Magnetization transfer ratio measurements of the brain in children with tuberous sclerosis complex. Pediatr Radiol 35:1071-1074. 